\title{
Insights into the role of soot aerosols in cirrus cloud formation
}

\author{
B. Kärcher ${ }^{1}$, O. Möhler ${ }^{2}$, P. J. DeMott ${ }^{3}$, S. Pechtt ${ }^{4, *}$, and F. Yu ${ }^{5}$ \\ ${ }^{1}$ Deutsches Zentrum für Luft- und Raumfahrt (DLR), Institut für Physik der Atmosphäre (IPA), Oberpfaffenhofen, Germany \\ ${ }^{2}$ Forschungszentrum Karlsruhe, Institut für Meteorologie und Klimaforschung (IMK-AAF), Karlsruhe, Germany \\ ${ }^{3}$ Department of Atmospheric Science, Colorado State University, Fort Collins, CO, 80523, USA \\ ${ }^{4}$ Ruprecht-Karls-Universität Heidelberg, Institut für Umweltphysik (IUP), Heidelberg, Germany \\ ${ }^{5}$ State University of New York at Albany (SUNY), Atmospheric Sciences Research Center (ASRC), NY, USA \\ *now at: Deutsches Patent- und Markenamt, München, Germany
}

Received: 4 May 2007 - Published in Atmos. Chem. Phys. Discuss.: 4 June 2007

Revised: 17 August 2007 - Accepted: 17 August 2007 - Published: 17 August 2007

\begin{abstract}
Cirrus cloud formation is believed to be dominated by homogeneous freezing of supercooled liquid aerosols in many instances. Heterogeneous ice nuclei such as mineral dust, metallic, and soot particles, and some crystalline solids within partially soluble aerosols are suspected to modulate cirrus properties. Among those, the role of ubiquitous soot particles is perhaps the least understood. Because aviation is a major source of upper tropospheric soot particles, we put emphasis on ice formation in dispersing aircraft plumes. The effect of aircraft soot on cirrus formation in the absence of contrails is highly complex and depends on a wide array of emission and environmental parameters. We use a microphysical-chemical model predicting the formation of internally mixed, soot-containing particles up to two days after emission, and suggest two principal scenarios: high concentrations of original soot emissions could slightly increase the number of ice crystals; low concentrations of particles originating from coagulation of emitted soot with background aerosols could lead to a significant reduction in ice crystal number. Both scenarios assume soot particles to be moderate ice nuclei relative to cirrus formation by homogeneous freezing in the presence of few efficient dust ice nuclei. A critical discussion of laboratory experiments reveals that the ice nucleation efficiency of soot particles depends strongly on their source, and, by inference, on atmospheric aging processes. Mass and chemistry of soluble surface coatings appear to be crucial factors. Immersed soot particles tend to be poor ice nuclei, some bare ones nucleate ice at low supersaturations. However, a fundamental understanding of these studies is lacking, rendering extrapolations to atmospheric conditions speculative. In particular, we cannot yet decide which indirect aircraft effect scenario is more plausible, and options suggested to mitigate the problem remain uncertain.
\end{abstract}

Correspondence to: B. Kärcher

(bernd.kaercher@dlr.de)

\section{Introduction}

Soot particles are ubiquitous in the atmosphere. They are produced by biomass burning and incomplete combustion of fossil fuels. Fresh soot particles consist of spherical primary particles that aggregate into larger clusters of fractallike shape. They are usually associated with organic and inorganic soluble material at their surfaces. Soot particles potentially serve as cloud condensation and ice nuclei, thereby affecting the formation of tropospheric clouds.

Soot aerosols have been detected with wire impactors in the troposphere and lower stratosphere (Pueschel et al., 1992; Blake and Kato, 1995; Strawa et al., 1999; Clarke et al., 2004). More detailed in-situ measurements of ambient black carbon-containing aerosols by selective detection of single particles using laser-induced incandescence have become available only recently (Baumgardner et al., 2004; Schwarz et al., 2006). Owing to their capability to strongly absorb sunlight (Liu and Mishchenko, 2005; Schnaiter et al., 2005), soot particles modify clouds and climate (Ackerman et al., 2000; Jacobson, 2001; Hansen and Nazarenko, 2004; Johnson et al., 2004; Roeckner et al., 2006).

In the upper troposphere, soot emissions from jet aircraft engines likely enhance the background concentrations of carbonaceous particles by number in major flight corridors (Hendricks et al., 2004, 2005). The abundance of carboncontaining aerosol decreases rapidly above the tropopause (Murphy et al., 2006, 2007). Ice forming ability and number density are key factors controlling their effect on high cloudiness. Therefore, studies that address the role of soot particles in cirrus formation ought to pay special attention to the specific, aircraft-induced perturbation. Besides cirrus modification, another motivation for understanding soot processes is that aircraft operations fall under stringent international regulations for environmental effects and changes in engine technologies for mitigation purposes have rather long lead times.

Published by Copernicus Publications on behalf of the European Geosciences Union. 
After some general remarks highlighting the various aspects of how aviation affects cirrus cloudiness, i.e. directly via contrail formation or indirectly via soot emissions, we focus on the indirect effect of soot particles and explain the approach taken in this study.

\subsection{Impact of aviation on cirrus cloudiness}

Aircraft influence high clouds by directly producing contrails that persist and spread in ice supersaturated air and by injecting soot particles that may act as heterogeneous ice nuclei (IN) after emission and affect cirrus cloud formation and evolution. The aim of this introductory section is to provide a clear distinction between contrail-induced and soot-induced cirrus clouds.

\section{Direct (contrail) effect}

Several studies have investigated the climatic impact of young (line-shaped) contrails, yielding large differences in predicted radiative forcing (Minnis et al., 1999; Ponater et al., 2002; Marquart et al., 2003; Sausen et al., 2005; Stuber et al., 2006). To date, estimates of the global radiative forcing caused by spreading, persistent contrails or from aircraft soot-induced cloud changes are not available (Wuebbles et al., 2007). Line-shaped jet contrails from aircraft cruising in the tropopause region are composed of $\mu \mathrm{m}$-sized ice crystals and are easily distinguished from natural high clouds. Soot particles emitted by jet engines are mainly responsible for their generation within one wingspan behind the aircraft (Kärcher et al., 1995, 1996). Factors controlling jet contrail formation are reasonably well known, although uncertainties exist concerning details of the ice crystal size distribution and optical properties, and hence their radiative forcing.

Persistent contrails grow into larger cirrus sheets (contrail cirrus) by the combined action of wind shear, turbulent mixing with ambient air, ice supersaturation, and depositional growth and sedimentation of ice crystals (Jensen et al., 1998). They often organize themselves in long-lived, regional-scale clusters (contrail outbreaks). Contrail cirrus exert a direct radiative forcing likely different from background cirrus because of differences in duration, extent, and ice crystal number and size. Besides some lidar data and regional information drawn from satellite observations, virtually no in-situ data is available for contrails older than a few minutes. It is likely that contrail cirrus coverage exceeds the coverage of line-shaped contrails, hence the climate impact of contrail cirrus might be larger than previously thought. This issue clearly warrants further studies.

\section{Indirect (soot) effect}

Soot particles emitted by aircraft jet engines may also perturb cirrus properties and alter cirrus coverage without contrail formation being involved. Our study addresses important aspects of this indirect effect. Like contrail cirrus, exhaust soot particles are advected with the wind field over large distances, sometimes into regions without air traffic. The perturbation likely occurs on regional or smaller scales, because the residence time of aerosols in the tropopause region is of the order of days to few weeks, depending on the location of the emission relative to the tropopause, season, and latitude. The magnitude of the perturbation (e.g. changes in ice cloud particle effective radius) depends on the ice-forming ability of soot particles that interact with ambient aerosols, on the efficiency of aerosol particles to nucleate ice, on the abundance of water vapor $\left(\mathrm{H}_{2} \mathrm{O}\right)$, and on dynamic processes setting the stage for the generation of clouds in ice supersaturated regions. While measurements have demonstrated that upper tropospheric air masses are frequently supersaturated, global prediction of ice supersaturation is still at its infancy. This lack of predictive capability severely limits our ability to accurately simulate cirrus clouds in large-scale models in general.

\section{Coupling effects}

We underscore that contrail cirrus can exert an indirect effect on cirrus on their own. If cirrus clouds form in the presence of contrail cirrus, the background cirrus may have different properties, because its crystals nucleate in regions with preexisting ice. Contrail cirrus may compete with background cirrus for the available water vapor, altering its microphysical and optical properties. The situation is further complicated by the fact that background cirrus itself might be affected by aged aircraft soot emissions in heavily traveled aircraft corridors.

It is conceivable that the indirect effect occurs at times along with contrail cirrus, because contrail cirrus need ice supersaturation to persist and grow, which in turn facilitates ice formation at low supersaturations. It is therefore important to study both the direct radiative effect of contrail cirrus including associated changes in background cirrus and the indirect microphysical effect of soot aerosol or other anthropogenic and natural IN on cirrus cloudiness. We reiterate this interdependency of direct and indirect effects at the end of this work.

\subsection{Indirect effect of aircraft soot on cirrus}

On the premise that aircraft soot particles are more effective IN than liquid aerosol particles and that cirrus formation is dynamically triggered by slow synoptic uplift, cloudresolving simulations have shown that the resulting cirrus are more stable and have different areal coverage and optical properties than cirrus formed on liquid particles in the absence of aircraft soot (Jensen and Toon, 1997). More recent reviews have reported little progress on this subject since then (Kärcher, 2000; Schumann, 2005).

The main problem associated with assessing the role of aircraft soot in cirrus cloud formation is to unambiguously 
demonstrate that ice nucleates (mainly) on the exhaust soot particles, or those affected by the soot, sulfur, and organic emissions via coagulation and condensation. Designing airborne measurements that help resolve this problem is a challenging enterprise. Heterogeneous ice nucleation rates of soot and other insoluble particles are not well known (Cantrell and Heymsfield, 2005). There is experimental evidence that cirrus ice crystal residues sampled and analyzed within aircraft corridors contain soot (Ström and Ohlsson, 1998), but this observation alone is insufficient to demonstrate that soot particles have actually played a role in the process of ice formation. Instead, soot could be included as a passive tracer within freezing aerosol particles or could be scavenged by ice crystals after the cloud has formed.

Atmospheric variability in vertical winds below the synoptic scale often seems to control the cooling rates of air parcels containing ice-forming particles (Kärcher and Ström, 2003), questioning the validity of the common assumption that cirrus formation is triggered by slow synoptic uplift. The cooling rate history determines the relative contributions of different ice nucleation pathways, i.e., which and how many aerosol particles contribute to cirrus ice (DeMott et al., 1997; Kärcher et al., 2006). Atmospheric cooling rates are difficult to determine experimentally and to describe and predict by models. Taken together, this renders a separate experimental evaluation of dynamical and aerosol effects on cirrus formation very difficult.

\subsection{Approach taken in this study}

We investigate the evolution of aircraft-generated soot aerosols up to two days after emission in upper tropospheric or lower stratospheric conditions in the absence of contrails. Coagulation and condensation processes change the size distribution and the chemical composition of the soot particles, which are key factors controlling their ice nucleation efficiency (Kärcher, 1999). We relate our computational results concerning the physical properties, mixing state, and chemical composition of plume particles to experimental studies of the ice nucleation behavior of pure and coated (internally mixed) soot particles, including the most recent scientific developments. These laboratory studies encompass a suite of surface and morphological properties of soot particles, which also affect ice nucleation and are difficult to address theoretically. The few available field studies suggest a minor role of soot acting as upper tropospheric IN, but the current data base is insufficient to draw a solid conclusion.

Without a detailed understanding of these issues, a sound assessment of the associated cloud impact remains speculative. We believe that our approach provides new insights into the potential for soot from aircraft and other sources to alter cirrus and forms a solid basis for further studies. The actual simulation of cloud is beyond the scope of this work; here, we will discuss important results on the concentration and freezing regimes in which soot particles might be capable of modifying the cirrus cloud formation process.

In detail, we investigate the factors controlling the generation of internally mixed aircraft soot particles that may act as IN for cirrus formation while the emissions spread on a regional scale. For this purpose, we employ a Lagrangian plume model with interactive entrainment of constituents present in ambient air, gas phase sulfur chemistry and condensation, and coagulation between particles of different size and composition. We vary variables influencing the ice nucleating ability of aviation soot, such as the fuel sulfur content (FSC) or properties of the ambient particle population. We keep other variables constant to which our results are not sensitive or whose average behavior is sufficiently well known. Figure 1 schematically depicts the array of processes realized in our model.

Throughout this work, we assume an air pressure $(p)$ of $250 \mathrm{hPa}$ and a temperature $(T)$ of $220 \mathrm{~K}$ (values typical for midlatitude flight levels), both in ambient air and within the dispersing aircraft plume. The processes noted above are not very sensitive to changes in $p$ and $T$ at subsonic cruise altitudes $(8-13 \mathrm{~km})$. We initialize our calculations with aircraftinduced volatile and nonvolatile particles and gaseous sulfur dioxide $\left(\mathrm{SO}_{2}\right)$ and sulfuric acid $\left(\mathrm{H}_{2} \mathrm{SO}_{4}\right)$ emissions at a plume age of $10 \mathrm{~s}$, representing the end of the jet regime. At this stage of plume development, meteorological parameters have approached ambient conditions and effects of ionization on interactions between vapor molecules and particles have decayed. In the ambient air surrounding the plume, a constant concentration of $\mathrm{SO}_{2}$ and the size distributions and chemical composition of background aerosol particles are prescribed. Organic matter is associated with both aircraftproduced and background aerosols.

The rates of dilution of aircraft emissions and the associated rates of entrainment of ambient species are timedependent. In the expanding plume, particles change their chemical composition and size distributions through condensation and coagulation processes. Emitted and entrained $\mathrm{SO}_{2}$ is oxidized to $\mathrm{H}_{2} \mathrm{SO}_{4}$ via hydroxyl $(\mathrm{OH})$ radicals during daytime, and $\mathrm{H}_{2} \mathrm{SO}_{4}$ subsequently condenses onto the particles. Any soluble mass fraction in particles quickly equilibrates with ambient water vapor $\left(\mathrm{H}_{2} \mathrm{O}\right)$. We track these processes over a time span of $48 \mathrm{~h}$. The average plume encounter time in the North Atlantic flight corridor is $1-2 \mathrm{~d}$ (Kärcher and Meilinger, 1998), after which our results could be used as guidance to initialize aircraft emissions in global models.

Section 2 describes the model, its initialization with the help of a near-field model, and potential uncertainties involved in the simulations. Section 3 presents and discusses the model results. Section 4 reviews and critically discusses laboratory evidence of heterogeneous ice nucleation on soot, dust, and mixed-phase particles, delineates the implications for cirrus formation, and highlights possible options to mitigate indirect soot effects on cirrus. The main findings are briefly summarized at the end of most subsections in Sects. 3 


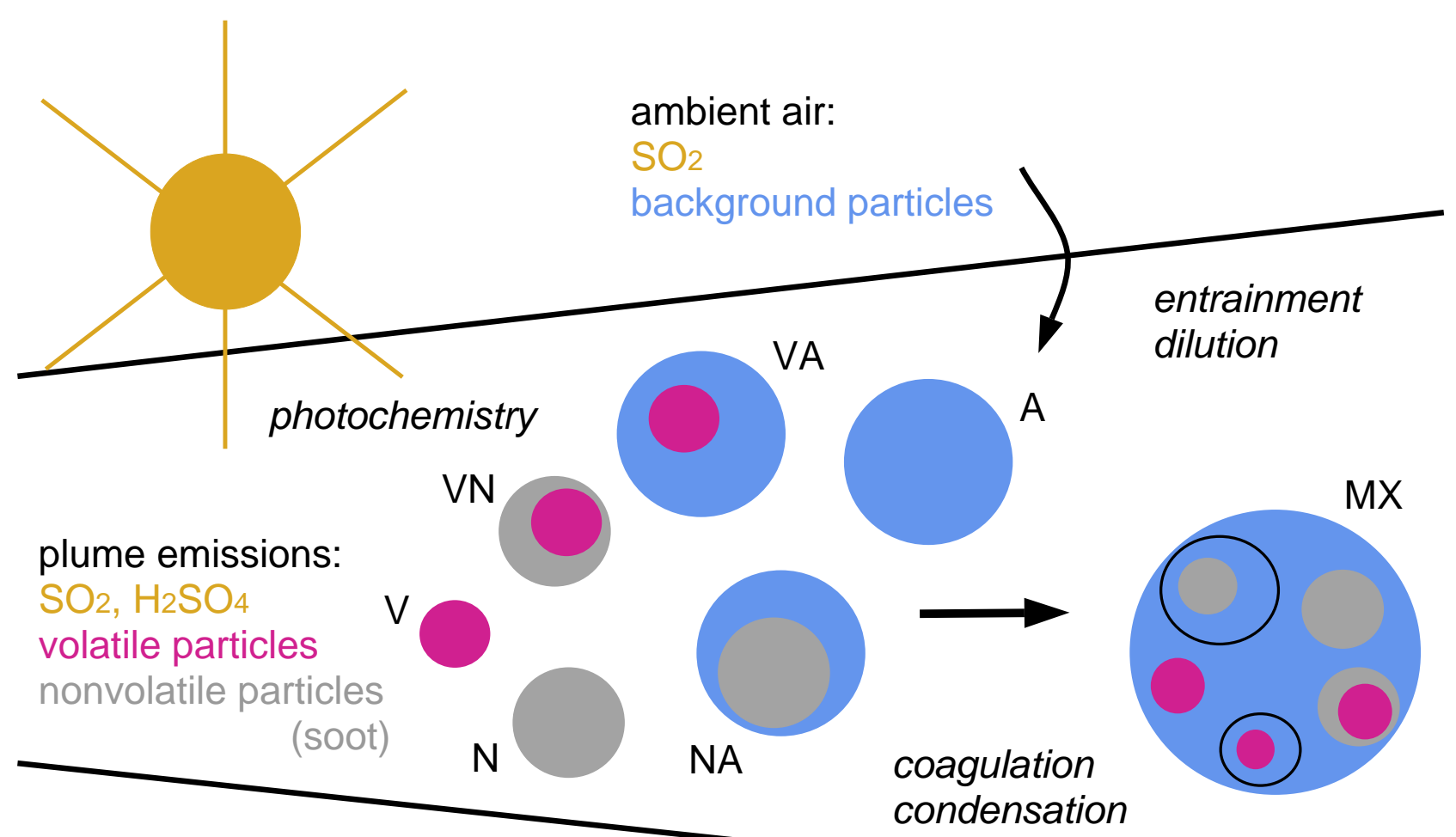

Fig. 1. Schematic of the dynamical, chemical, and microphysical processes leading to the formation of internally mixed soot particles containing black carbon from various sources in dispersing aircraft exhaust plumes. These processes are realized in a Lagrangian far-field plume model. Details are discussed in Sect. 2, supplemented by the information given in Tables 1-3. The key scientific questions are: (i) What is the time-dependent composition and concentration of the BC-containing particles? (ii) Under which conditions do these particles initiate the ice phase in cirrus clouds relative to unperturbed background particles?

Table 1. Lognormal size distribution parameters (total number density $n$, dry median diameter $D_{d}$, geometric standard deviation $\sigma$ ) and non-water species volume fractions for aircraft nonvolatile particles $(\mathrm{N})$ at a plume age of $10 \mathrm{~s}$ and four background aerosol particle types. The latter consist of a wintertime (WIN) and a summertime distribution (SUM), a distribution following homogeneous aerosol nucleation (NUC), and a strongly accumulated distribution (ACC). Data for emission indices of chemi-ions and condensable organics (OM), as well as the efficiency with which fuel sulfur is converted to condensable $\mathrm{H}_{2} \mathrm{SO}_{4}$ (SA) at emission are given in Sect. 2.1. Characteristics of aircraft and ambient black carbon (BC) particles are also outlined in Sect. 2.1. Concentrations of gas phase $\mathrm{SO}_{2}$ and $\mathrm{H}_{2} \mathrm{SO}_{4}$ and size-averaged volume fractions of $\mathrm{BC}$ in nonvolatile aircraft particles are listed in Table 2. The simulated size distributions for volatile aircraft particles at $10 \mathrm{~s}$ (not included here but shown in Fig. 2) are not strictly lognormal and their species volume fractions are size-dependent.

\begin{tabular}{cccccccccc}
\hline & \multicolumn{3}{c}{ mode 1 } & \multicolumn{3}{c}{ mode 2 } & \multicolumn{3}{c}{ volume fraction, \% } \\
& $n, \mathrm{~cm}^{-3}$ & $D_{d}, \mathrm{~nm}$ & $\sigma$ & $n, \mathrm{~cm}^{-3}$ & $D_{d}, \mathrm{~nm}$ & $\sigma$ & $\mathrm{SA}$ & $\mathrm{OM}^{\mathrm{a}}$ & $\mathrm{BC}^{\mathrm{a}}$ \\
\hline $\mathrm{N}^{\mathrm{b}}$ & 5230 & 25 & 1.55 & 2 & 150 & 1.65 & & variable \\
$\mathrm{WIN}$ & 400 & 20 & 2.4 & 0.006 & 760 & 1.88 & 20 & 4 & 0.2337 \\
$\mathrm{SUM}$ & 800 & 40 & 2.1 & 0.2 & 800 & 1.8 & 20 & 4 & 0.0747 \\
$\mathrm{NUC}$ & 2200 & 11 & 1.7 & 40 & 50 & 1.8 & 17.5 & 3.5 & 2.0953 \\
$\mathrm{ACC}^{\mathrm{c}}$ & 50 & 15 & 2 & 220 & 115 & 1.45 & 17.5 & 3.5 & 0.0644 \\
\hline
\end{tabular}

\footnotetext{
a individually tracked in aircraft soot and background aerosol

${ }^{b}$ based on near-field simulations, see Fig. 2

${ }^{c}$ in addition third mode equal to mode 2 from summer distribution, see Fig. 3
} 
$0.01 \mathrm{~g} \mathrm{~S} / \mathrm{kg}$-fuel
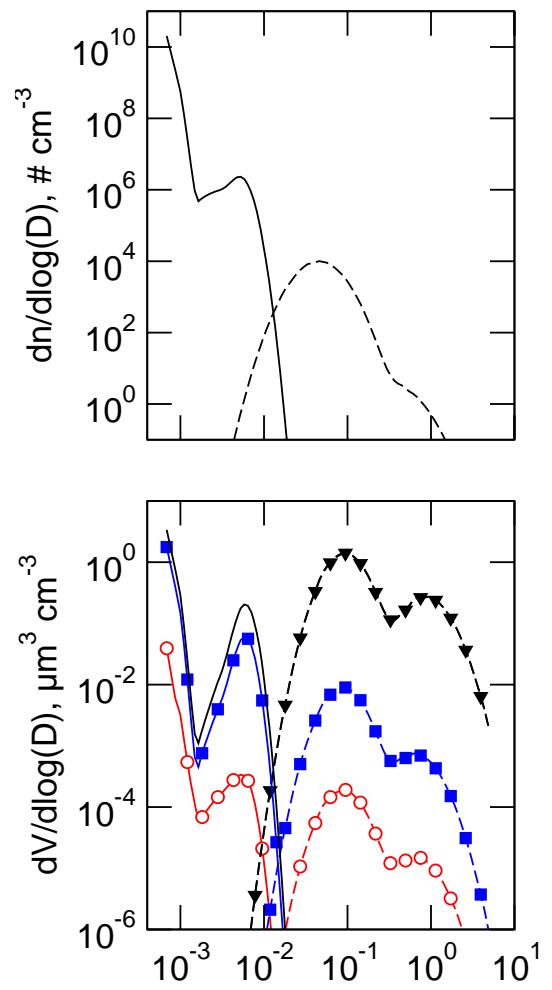

$0.1 \mathrm{~g} \mathrm{~S} / \mathrm{kg}$-fuel
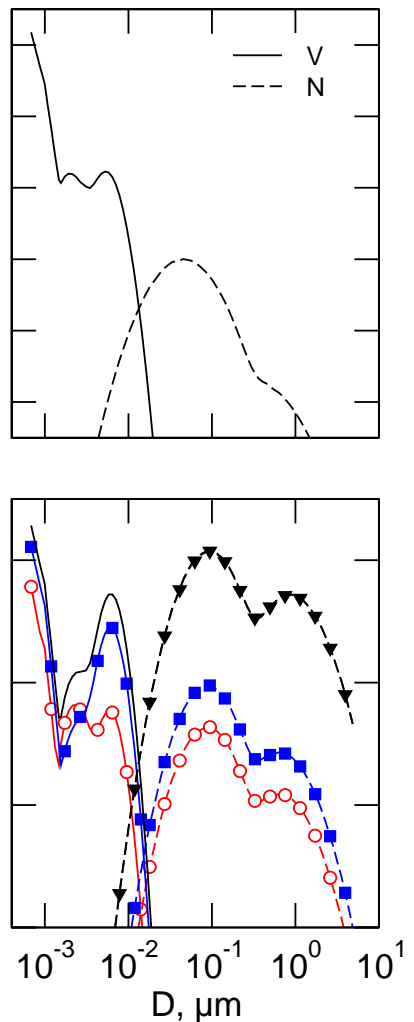

$1 \mathrm{~g} \mathrm{~S} / \mathrm{kg}$-fuel
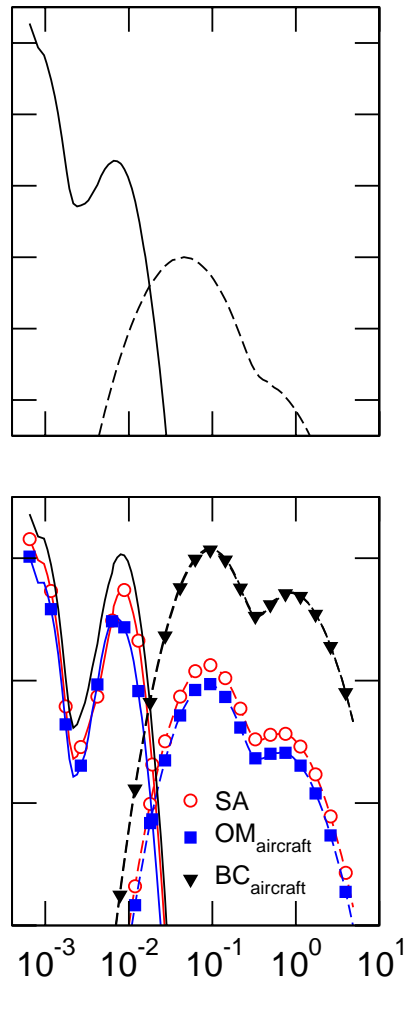

Fig. 2. Particle size (top panel) and volume (bottom panel) distributions of volatile (solid curves) and nonvolatile (dashed curves) aircraft emissions taken at a plume age of $10 \mathrm{~s}$. These results are taken from a near-field plume model assuming mixing properties and emissions typical for a cruising airplane.

and 4. The uncertainties associated with soot-induced ice formation are collected in a table for easy reference. Section 5 concludes this work with recommendations for future research.

\section{Model framework}

\subsection{Aerosol characterization}

\subsubsection{Aircraft-induced aerosols}

Initial aerosol particle size and volume distributions emitted by aircraft in flight for three different FSCs are shown in Fig. 2. The value of $0.1 \mathrm{~g} \mathrm{~S} / \mathrm{kg}$-fuel is closest to the range of the global fleet average $(0.2-0.4 \mathrm{~g} \mathrm{~S} / \mathrm{kg}$-fuel), which shows a tendency to decrease over time. Hence, the medium FSC case can be considered a lower limit of current average conditions. The low and high $\mathrm{S}$ emission cases cause differences in the partitioning of $\mathrm{H}_{2} \mathrm{SO}_{4}$ and black carbon (BC) in particles, which we like to investigate. In all cases, an S-to$\mathrm{H}_{2} \mathrm{SO}_{4}$ conversion efficiency at emission of $3 \%$, chemi-ion emissions of $2 \times 10^{17} / \mathrm{kg}$-fuel, and particulate organics with an emission index of $20 \mathrm{mg} / \mathrm{kg}$-fuel (see below) have been prescribed, consistent with a large body of in-situ observations (Kärcher et al., 2000). Most of the organic emissions probably consist of condensable aldehydes (Yu et al., 1999), but as their exact chemical composition is not known, we treat all of the potential particle-forming organics generically as organic matter $\left(\mathrm{OM}_{\text {aircraft }}\right)$. The proposed initialization is largely consistent with studies of the influence of fuel sulfur on the composition of aircraft exhaust plumes (Schumann et al., 2002).

The gaseous and particulate emissions up to a plume age of $10 \mathrm{~s}$ have been calculated using a comprehensive chemicalmicrophysical near-field model (Yu et al., 1999). The results at $10 \mathrm{~s}$ serve as an initialization of the far-field plume model whose elements are sketched in Fig. 1. The nearfield jet model accounts for charge effects on aerosol nucleation and growth caused by chemi-ion emissions within the framework of a multicomponent, size-resolved, kineticallycontrolled vapor/aerosol system. Besides $\mathrm{OM}_{\text {aircraft, }}$ it includes aqueous $\mathrm{H}_{2} \mathrm{SO}_{4}$ aerosols (SA), black carbon soot particles $\left(\mathrm{BC}_{\text {aircraft }}\right)$, gaseous organic and $\mathrm{SO}_{2}$ emissions, and $\mathrm{SO}_{2}$ chemistry building up gas phase $\mathrm{H}_{2} \mathrm{SO}_{4}$ in addition to emitted $\mathrm{H}_{2} \mathrm{SO}_{4}$. Turbulent mixing, coagulation, and water equilibrium are treated similar to the far-field model, see Sects. 2.2-2.4. 
Table 2. Number concentrations of emitted $\mathrm{SO}_{2}$ and $\mathrm{H}_{2} \mathrm{SO}_{4}$ remaining in the gas phase after volatile particle formation and gas phase oxidation for different fuel sulfur contents. Also given are the size-averaged volume fractions of the chemical components of the nonvolatile aircraft particles, the distributions of which are shown in Fig. 2. The values are taken from the near-field simulations at a plume age of $10 \mathrm{~s}$.

\begin{tabular}{cccccc}
\hline $\begin{array}{c}\text { FSC, } \\
\text { g S/kg-fuel }\end{array}$ & $\begin{array}{c}{\left[\mathrm{SO}_{2}\right],} \\
\mathrm{cm}^{-3}\end{array}$ & $\begin{array}{c}{\left[\mathrm{H}_{2} \mathrm{SO}_{4}\right],} \\
\mathrm{cm}^{-3}\end{array}$ & $\begin{array}{c}\mathrm{SA}, \\
\%\end{array}$ & $\begin{array}{c}\mathrm{OM}, \\
\%\end{array}$ & $\begin{array}{c}\mathrm{BC}, \\
\%\end{array}$ \\
\hline 0.01 & $1.4 \times 10^{9}$ & $3.3 \times 10^{7}$ & 0.012 & 0.54 & 97.64 \\
0.1 & $1.4 \times 10^{10}$ & $3.2 \times 10^{8}$ & 0.11 & 0.54 & 97.33 \\
1 & $1.4 \times 10^{11}$ & $1.9 \times 10^{9}$ & 1.08 & 0.53 & 94.26 \\
\hline
\end{tabular}

As seen in Fig. 2, the particle emissions consist of a volatile mode $\mathrm{V}$ (solid curves) composed of SA, $\mathrm{OM}_{\text {aircraft }}$, and water, and a nonvolatile mode $\mathrm{N}$ (dashed curves) additionally composed of $\mathrm{BC}_{\text {aircraft }}$. Also shown are the volume concentrations of all chemical species in particles except water (curves with symbols). All volatile number distributions exhibit a pronounced mode at the smallest sizes, consisting of subcritical neutral organic and sulfuric acid molecular clusters. The initial tendency for $\mathrm{H}_{2} \mathrm{SO}_{4}$ to collect on negatively charged ions and particles and that for organic vapors to collect on positively charged species leads to additional, chemiion-induced volatile modes with diameters up to $10 \mathrm{~nm}$. Figure 2 shows that organic emissions contribute a significant fraction of the total volatile aerosol volume, even in the high FSC case. Black carbon constitutes most of the volume of the nonvolatile particles $(>95 \%)$. We use a soot emission index of $10 \mathrm{mg} / \mathrm{kg}$-fuel at the low end of reported values to account for the tendency of modern jet engines to generate a smaller BC particle mass. Observed soot particle size distributions appear to consist of two lognormal modes (Petzold et al., 1999), as also assumed in this study (Table 1), and show little variability among modern aircraft. Because of the difficulty to measure ultrafine particle properties, however, the size distributions of aircraft soot emissions remain uncertain. Vapor condensation and scavenging of small volatile particles causes BC particles to become internally mixed with $\mathrm{OM}$ and SA (Kärcher et al., 1996). Increasing FSC enhances concentrations of $\mathrm{H}_{2} \mathrm{SO}_{4}$ in the early plume and leads to larger SA volume fractions in soot particles that have not yet interacted with background aerosols (Table 2 and Fig. 2).

\subsubsection{Background aerosols}

The background aerosol number and volume size distributions are shown in Fig. 3, representing different stages in the life cycle of free tropospheric aerosols at northern midlatitudes. Based on a climatology of aerosol properties taken over the continental USA, we select typical winter (WIN) and summer (SUM) distributions, which differ in mean size and total number of particles but less in the shape of the size spectrum (Hofmann, 1993). This distinction is important, because tropospheric aerosols exhibit a marked seasonal cycle. Further, the interaction with clouds is known to modify aerosol populations. We select an aerosol spectrum lacking large particles typical for air masses in which aerosol nucleation recently occurred (NUC), and contrast it with an accumulated aerosol stage (ACC) prior to cloud formation in which the majority of particles had sufficient time to grow to relatively large sizes in the absence of hydrometeors (Schröder et al., 2002). Differences in the size distributions between the four background cases (Table 1) imply variations in the scavenging efficiency of small, aircraftinduced particles, which we like to study.

The chemical composition of background aerosols is more difficult to assess (Law et al., 2006; Murphy et al., 2006). It seems likely that sulfate and organics (and their associated water) make up most of the aerosol particle volume, with organics contributing $10-50 \%$ of the solute mole fraction (Murphy et al., 1998). Data on the speciation of organic compounds is hardly available, but we distinguish between $\mathrm{OM}$ in ambient and aircraft aerosols, because particle freezing properties may depend on the organic composition. Because of the lack of more detailed information, we assume an $\mathrm{OM}_{\text {ambient }} / \mathrm{SA}$ molar ratio of 0.2 in all background particles (Table 1). The remaining water fraction in particles corresponds to relative humidities well below ice saturation, as detailed in Sect. 2.4.

According to recent in-situ measurements in the troposphere and lowermost stratosphere, ambient BC particles occur in the accumulation mode size range $(0.1-1 \mu \mathrm{m}$, lower sizes will become detectable in the future) with mass mixing ratios of the order $1-10 \mathrm{ng} / \mathrm{kg}$-air close to the tropopause (Schwarz et al., 2006). These observations also indicate that a significant fraction of $\mathrm{BC}$ particles are internally mixed or coated. Other measurements carried out over the North Atlantic using condensation nuclei counters demonstrate that upper tropospheric concentrations of nonvolatile condensation nuclei (presumably containing BC) are surprisingly high, i.e. in the range $10-30 \mathrm{~cm}^{-3}$ (Minikin et al., 2003). It is not yet clear how representative these data are. We assume constant $\mathrm{BC}_{\mathrm{ambient}}$ volume fractions in background particles over the entire size range (Table 1), leading to a total ambient $\mathrm{BC}$ mass of $2.5 \mathrm{ng} / \mathrm{kg}$-air in the winter case and $7.5 \mathrm{ng} / \mathrm{kg}$ air in all other cases. These $\mathrm{BC}_{\text {ambient }}$ values correspond to annual mean concentrations in the North Atlantic flight corridor predicted by a global model (Hendricks et al., 2004). To compute BC mass concentrations from simulated volume concentrations, we use a bulk mass density of $1.8 \mathrm{~g} \mathrm{~cm}^{-3}$.

Aerosol organic carbon (OC) to black carbon ratios in ambient soot particles typically range between 1 to 3 according to lower tropospheric measurements (Novakov et al., 2005). High OC/BC ratios up to 25 systematically occur only with low BC mass concentrations. There are several uncertainties 

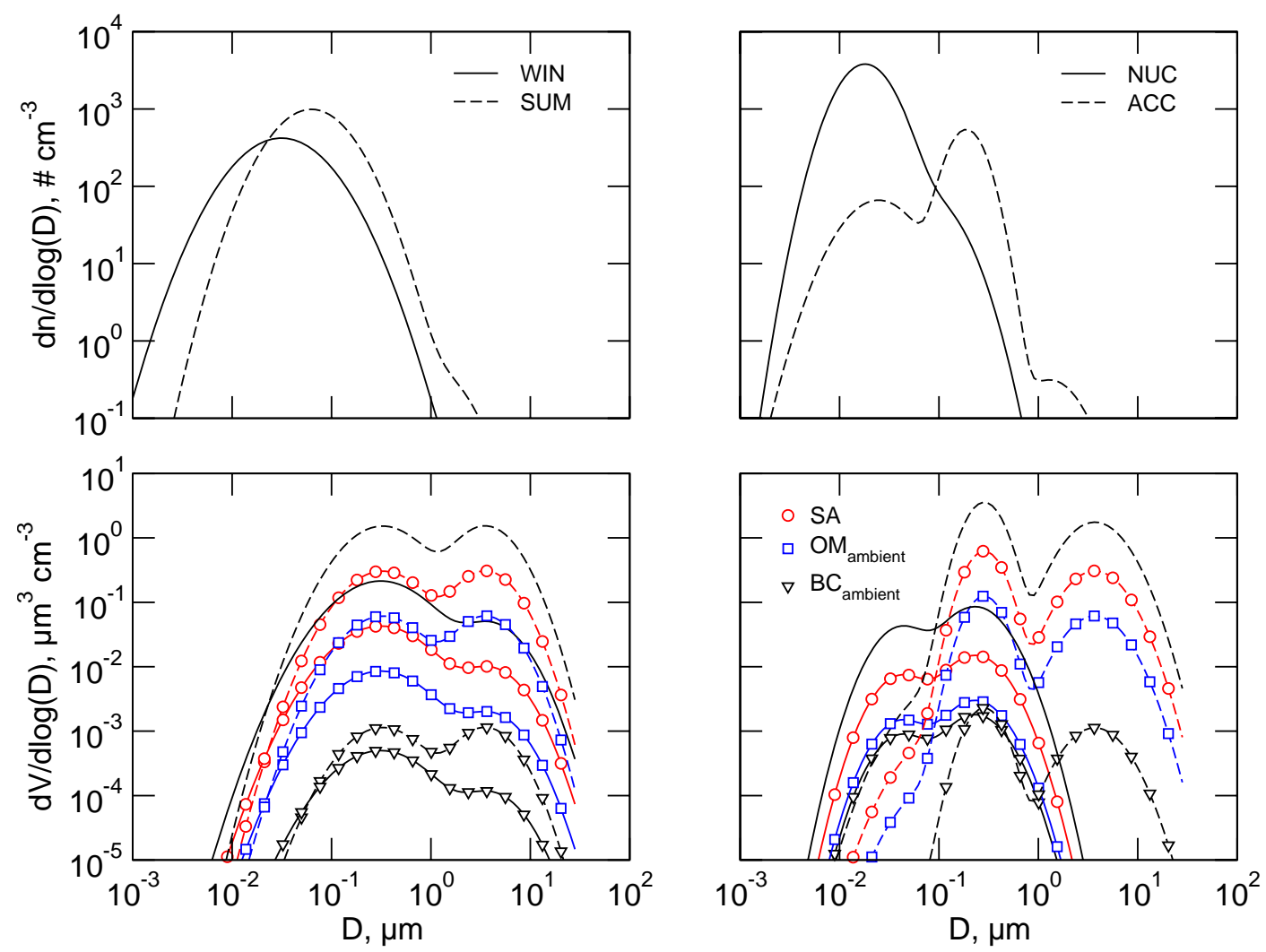

Fig. 3. As in Fig. 2, but for background aerosols. Shown are four distinct free tropospheric cases describing typical midlatitude winter (solid curves) and summer (dashed curves) distributions in the left panel, and distributions found after new particle formation (solid curves) and before cloud formation (dashed curves) in the right panel.

associated with these measurements, among which is the difference between OC and OM (organic matter may contain other species besides carbon). In our background particles, the $\mathrm{OM} / \mathrm{BC}$ ratios range between 1.7 and 62 (Table 1). It seems plausible that the $\mathrm{OM} / \mathrm{BC}$ ratio in particles increases as they age and are transported into the upper troposphere, due to condensation of low-volatile organic vapors. In sum, our assumptions about the relative amounts of SA, $\mathrm{OM}_{\text {ambient }}$, and $\mathrm{BC}_{\mathrm{ambient}}$ and their distribution over particle size appear to be plausible, but cannot be accurately constrained by current observations.

\subsection{Entrainment and dilution}

The generic equation governing the time history of a tracer mixing ratio $\chi$ in a dispersing plume is given by

$\frac{d \chi}{d t}=-\omega(t)\left(\chi-\chi_{b}\right)$

where $\omega$ denotes the entrainment (or dilution) rate and the subscript $b$ abbreviates background. The solution of Eq. (1) reads

$\chi(t)=\chi_{b}+\mathcal{D}(t)\left(\chi_{o}-\chi_{b}\right)$, the subscript $o$ denoting an initial condition. The dilution factor follows from

$\mathcal{D}(t)=\mathcal{D}_{o} \exp \left[-\int_{t_{o}}^{t} \omega(t) d t\right]$.

At the end of the jet regime at $t_{o}=10 \mathrm{~s}, \mathcal{D}_{o}=0.001$. We use a constant value $\omega_{o}=0.005 \mathrm{~s}^{-1}$ at plume ages between $10 \mathrm{~s}$ and $2 \mathrm{~min}$ and the power law function $\omega=\alpha / t$ with $\alpha=0.8$ at later times (Kärcher, 1999, Fig. 4). These choices account for suppressed mixing in the wake vortex regime and an average plume expansion behavior in the following atmospheric dispersion regime guided by in-situ observations (Schumann et al., 1998) and large eddy simulations (Gerz et al., 1998). The mixing time scale $1 / \omega$ in the dispersion regime increases with time and is approximately equal to the plume age.

We integrate Eq. (1) analytically over one time step $\tau$, hence the discretized form of Eq. (2) reads

$\chi_{+}=\mathcal{D}_{\tau} \chi_{-}+\left(1-\mathcal{D}_{\tau}\right) \chi_{b}$

In Eq. (4), the subscripts + and - denote values at the next $(t+\tau)$ and actual $(t)$ time, respectively, and from Eq. (3) we have

$\mathcal{D}_{\tau}=\exp \left(-\omega_{0} \tau\right)$ 
WIN, $0.1 \mathrm{~g} \mathrm{~S} / \mathrm{kg}$-fuel
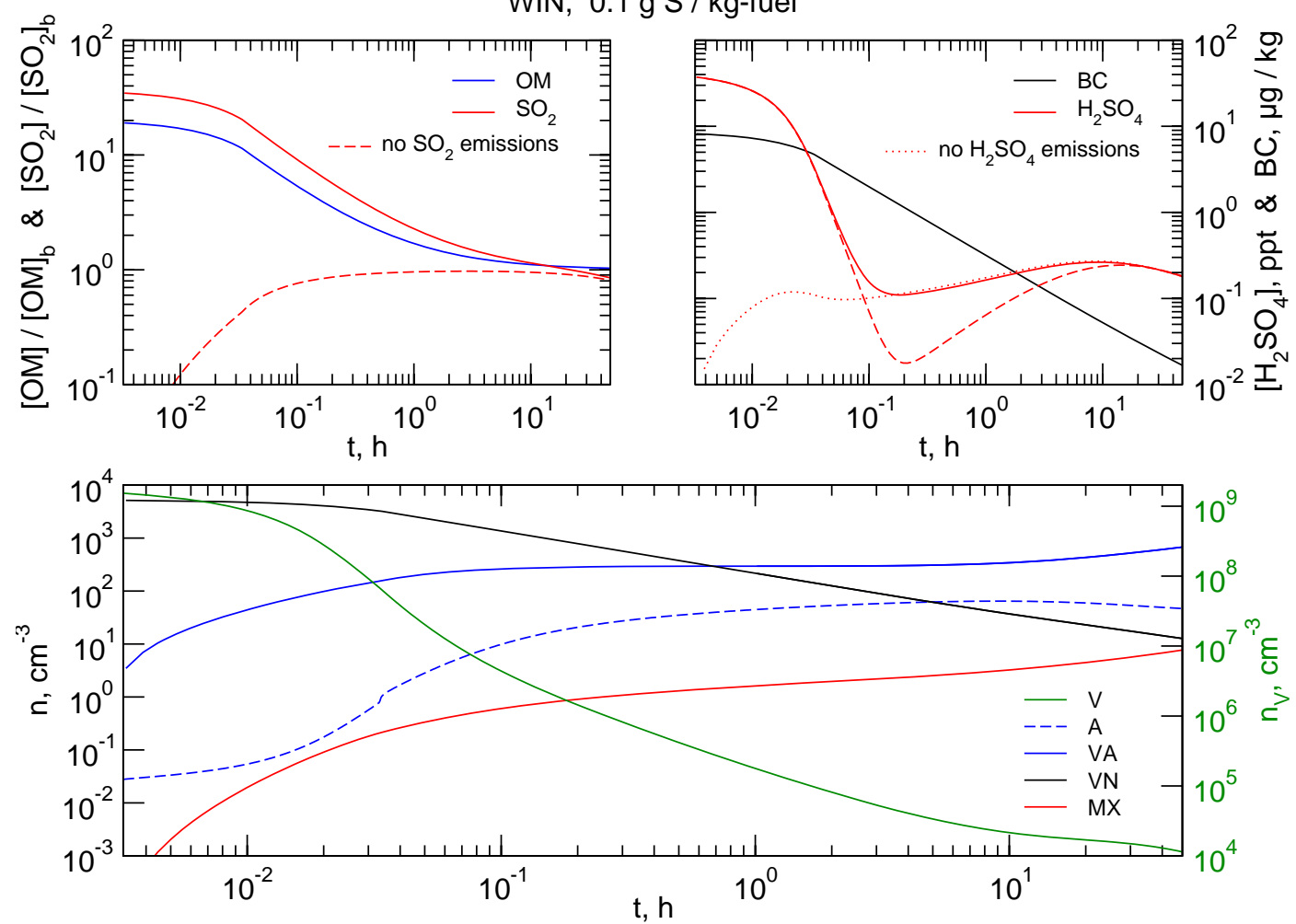

Fig. 4. Temporal evolution of total organic matter and $\mathrm{SO}_{2}$ mixing ratios (normalized to their background values, top left), $\mathrm{H}_{2} \mathrm{SO}_{4}$ and total black carbon mixing ratios (top right), and total number densities of selected plume particle types (bottom). Note the different concentration scales for $\mathrm{V}$ particles on the right-hand side. In the top panels, the dashed curves have been obtained by neglecting aircraft emissions of $\mathrm{SO}_{2}$, and the dotted curve neglects emissions of $\mathrm{H}_{2} \mathrm{SO}_{4}$. The results assume the wintertime background distribution and medium FSC.

in the vortex regime $(10 \mathrm{~s} \leq t \leq 2 \mathrm{~min})$ and

$\mathcal{D}_{\tau}(t)=\left(\frac{t}{t+\tau}\right)^{\alpha}$

in the dispersion regime ( $t>2 \mathrm{~min}$ ) for use in Eq. (4). As we keep $T$ and $p$ constant, Eqs. (1), (2), and (4) hold for number concentrations as well. The first term on the right side of Eq. (4) describes the dilution of all species (molecules and particles) present in the plume, and the second term describes entrainment of ambient $\mathrm{SO}_{2}$ and number and volume concentrations of background aerosol particles (curved arrow in Fig. 1). The plume cross section after 24 hours is of the order $10^{6} \mathrm{~m}^{2}$ (Kärcher, 1999).

\subsection{Coagulation}

We describe self- and hetero-coagulation over seven particle size distributions (Fig. 1) using a stationary size structure (Jacobson, 2002). The particle types used to initialize the simulations are shown in Fig. 2, the other plume distributions attain non-zero values after they are generated by coagulation processes. Aircraft-emitted volatile $(\mathrm{V})$ and nonvolatile $(\mathrm{N})$ aerosols and entrained background aerosols (A) heterocoagulate to form the binary mixtures VN, VA, and NA. Coagulation of $\mathrm{V}$ with $\mathrm{VN}$ or VA increases the volume of these binary distributions and constitutes a loss path for particles in the $\mathrm{V}$ distribution. The same holds for coagulation of $\mathrm{N}$ with $\mathrm{VN}$ or NA, and for coagulation of A with VA or NA. Once $\mathrm{V}$ and NA, N and VA, A and VN or any of the binary mixtures hetero-coagulate with each other, they generate a mixed distribution MX that contains the chemical components of all other distributions. In addition, all particles within each size distribution coagulate among themselves. These interactions are summarized in Table 3, along with a summary of the chemical components associated with each particle type. As for $\mathrm{OM}$, we distinguish between $\mathrm{BC}$ originating from aircraft emissions and from other sources to track them separately, as noted in Sect. 2.1. Sizes of particles containing BC are interpreted as those from volume-equivalent spheres.

With seven number concentrations and 42 species volume concentrations in particles that are distributed over 100 size bins, a total of 4900 coagulation equations are solved simultaneously. Coagulation kernels are used to describe particle interactions by Brownian motion, covering kinetic and diffusion regimes. Large values (close to unity) for the sticking coefficient $\beta$ for collisions involving neutral molecular monomers and small clusters are unlikely, for which reason we adopt reduced values for $\beta$ to describe coagulation between particles in the nm-size range (Yu and Turco, 1998). 
The expression we use here reads

$\beta=\min \left\{1, \beta_{\min }^{\ln \left(r_{*} / \sqrt{r_{i} r_{j}}\right) / \ln \left(r_{*} / r_{m}\right)}\right\}$

with $\beta_{\min }=0.01, r_{*}=0.6 \mathrm{~nm}$, and the radius of an $\mathrm{H}_{2} \mathrm{SO}_{4}$ molecule $r_{m}=0.277 \mathrm{~nm}$. The subscripts $i$ and $j$ denote different particle size bins, with $r_{m}$ being the radius of the smallest bin. Here, $\beta$ quickly approaches unity when the colliding particles have grown past a few nanometers.

\subsection{Chemistry and condensation}

The rate limiting step in the production of $\mathrm{H}_{2} \mathrm{SO}_{4}$ from $\mathrm{SO}_{2}$ in the gas phase is the oxidation of $\mathrm{SO}_{2}$ by $\mathrm{OH}$ (Stockwell and Calvert, 1983). Sulfuric acid may then condense onto aerosol particles via gas phase diffusion and accomodation, increasing the SA and total volume concentration of particles in each size bin. The governing equations are ([·] denoting number concentrations):

$$
\begin{aligned}
\frac{d\left[\mathrm{SO}_{2}\right]}{d t} & =-k\left[\mathrm{SO}_{2}\right] \\
\frac{d\left[\mathrm{H}_{2} \mathrm{SO}_{4}\right]}{d t} & =-\kappa\left[\mathrm{H}_{2} \mathrm{SO}_{4}\right]+k\left[\mathrm{SO}_{2}\right] \\
\frac{d\left[\mathrm{SA}_{\ell}\right]}{d t} & =\kappa_{\ell} v_{m}\left[\mathrm{H}_{2} \mathrm{SO}_{4}\right]
\end{aligned}
$$

where $k=\tilde{k}[\mathrm{OH}]$ and $\tilde{k}$ is the three-body rate coefficient for the gas phase reaction of $\mathrm{SO}_{2}$ and $\mathrm{OH}$ to produce $\mathrm{HSO}_{3}$ (immediately reacting further to eventually produce $\left.\mathrm{H}_{2} \mathrm{SO}_{4}\right), \ell$ is an index running over all particle types and size bins, $\kappa_{\ell}$ is the condensation rate proportional to the number concentration of particles of a given size and type, $\kappa=\sum_{\ell} \kappa_{\ell}$ is the total condensation rate of $\mathrm{H}_{2} \mathrm{SO}_{4},\left[\mathrm{SA}_{\ell}\right]$ denotes the volume concentration of $\mathrm{H}_{2} \mathrm{SO}_{4}$ in particles of a given size, and $v_{m}=4 \pi r_{m}^{3} / 3$.

For $[\mathrm{OH}]$ we use a daytime upper limit of $3 \times 10^{6} \mathrm{~cm}^{-3}$ and reduce this value by a factor of two to obtain a diurnal average. Together with the rate coefficient $\tilde{k} \simeq 1.5 \times$ $10^{-12} \mathrm{~cm}^{3} \mathrm{~s}^{-1}$, this determines $k$ and a chemical time scale $1 / k$ for production of $\mathrm{H}_{2} \mathrm{SO}_{4}$ in the gas phase of about $5 \mathrm{~d}$. For ambient $\left[\mathrm{SO}_{2}\right]$ we use $50 \mathrm{pptv}\left(4 \times 10^{8} \mathrm{~cm}^{-3}\right)$; this is close to the median mixing ratio measured with a novel airborne mass spectrometer over Europe during springtime 2006 (H. Schlager, personal communication, 2007). These observations also showed that $\left[\mathrm{SO}_{2}\right]$ ranges between 30 150 pptv at $10.5 \mathrm{~km}$ altitude (10 and $90 \%$ percentiles, respectively). The concentrations of emitted $\mathrm{H}_{2} \mathrm{SO}_{4}$ and $\mathrm{SO}_{2}$ obtained from the near-field simulations at $10 \mathrm{~s}$ are summarized in Table 2.

We use condensation rates $\kappa_{\ell}$ that are consistent with Brownian coagulation kernels and with Eq. (7). The condensation time scale $1 / \kappa$ ranges from $1 \mathrm{~min}$ at young plumes ages to $2 \mathrm{~h}$ toward the end of the simulations at plumes ages of $1-2 \mathrm{~d}$, mainly because dilution decreases the particle concentrations.
Table 3. Coagulation matrix referring to the plume particle types illustrated in Fig. 1. We deal with plume emissions (volatile particles $\mathrm{V}$, nonvolatile particles $\mathrm{N}$ ), ambient particles A entrained into and modified within the plume, and plume particles (binary types $\mathrm{VN}$, VA, NA, and MX) created by hetero-coagulation. For example, coagulation of $\mathrm{VN}$ with A particles produces MX particles. Below this matrix, the first row shows the chemical components associated with each type, whereby $\mathrm{W}$ denotes particulate $\mathrm{H}_{2} \mathrm{O}$.

\begin{tabular}{cccccccc}
\hline & V & N & A & VN & VA & NA & MX \\
\hline V & V & VN & VA & VN & VA & MX & MX \\
N & VN & N & NA & VN & MX & NA & MX \\
A & VA & NA & A & MX & VA & NA & MX \\
VN & VN & VN & MX & VN & MX & MX & MX \\
VA & VA & MX & VA & MX & VA & MX & MX \\
NA & MX & NA & NA & MX & MX & NA & MX \\
MX & MX & MX & MX & MX & MX & MX & MX \\
\hline W & $\times$ & $\times$ & $\times$ & $\times$ & $\times$ & $\times$ & $\times$ \\
SA & $\times$ & $\times$ & $\times$ & $\times$ & $\times$ & $\times$ & $\times$ \\
OM $_{\text {ambient }}$ & - & - & $\times$ & - & $\times$ & $\times$ & $\times$ \\
OM $_{\text {aircraft }}$ & $\times$ & $\times$ & - & $\times$ & $\times$ & $\times$ & $\times$ \\
BC $_{\text {ambient }}$ & - & - & $\times$ & - & $\times$ & $\times$ & $\times$ \\
BC $_{\text {aircraft }}$ & - & $\times$ & - & $\times$ & - & $\times$ & $\times$ \\
\hline
\end{tabular}

The system of chemical Eqs. (8)-(10) can be solved analytically over one time step to yield:

$$
\begin{aligned}
{\left[\mathrm{SO}_{2}\right]_{+} } & =\left[\mathrm{SO}_{2}\right]_{-} \exp (-k \tau) \\
{\left[\mathrm{H}_{2} \mathrm{SO}_{4}\right]_{+} } & =\left[\mathrm{H}_{2} \mathrm{SO}_{4}\right]_{-} \exp (-\kappa \tau) \\
& +K \cdot\left[\mathrm{SO}_{2}\right]_{-} \exp (-k \tau)\{1-\exp [-(\kappa-k) \tau]\}(12) \\
{\left[\mathrm{SA}_{\ell}\right]_{+} } & =\left[\mathrm{SA}_{\ell}\right]_{-}+v_{m}(\kappa \ell / \kappa) \\
& \times\left\{\left(\left[\mathrm{H}_{2} \mathrm{SO}_{4}\right]_{-}-K \cdot\left[\mathrm{SO}_{2}\right]_{-}\right)[1-\exp (-\kappa \tau)]\right. \\
& \left.+(K+1) \cdot\left[\mathrm{SO}_{2}\right]_{-}[1-\exp (-k \tau)]\right\}
\end{aligned}
$$

where $K=k /(\kappa-k)$. The specific case $\kappa=k$ does not apply to our problem (because $\kappa \gg k$ ), but for completeness we note these solutions as well (Eq. (11) remains unchanged):

$$
\begin{aligned}
{\left[\mathrm{H}_{2} \mathrm{SO}_{4}\right]_{+} } & =\left(\left[\mathrm{H}_{2} \mathrm{SO}_{4}\right]_{-}+\left[\mathrm{SO}_{2}\right]_{-} \kappa \tau\right) \exp (-\kappa \tau) \\
{\left[\mathrm{SA}_{\ell}\right]_{+} } & =\left[\mathrm{SA}_{\ell}\right]_{-}+v_{m}(\kappa \ell / \kappa) \\
& \times\left\{\left[\mathrm{H}_{2} \mathrm{SO}_{4}\right]_{-}[1-\exp (-\kappa \tau)]\right. \\
& \left.+\left[\mathrm{SO}_{2}\right]_{-}[1-(1+\kappa \tau) \exp (-\kappa \tau)]\right\} .
\end{aligned}
$$

Because the amount of soluble matter in particles changes due to coagulation and condensation of $\mathrm{H}_{2} \mathrm{SO}_{4}$, the associated water mass also changes with time. The compositiondependent aerosol water content determines the total particle size. Initially, together with the air temperature $T$, the equilibrium water fraction in background particles determines the 
$\mathrm{H}_{2} \mathrm{O}$ partial pressure $p_{w}$. This value corresponds to relative humidities in the range $45-55 \%$, depending on the background case. At these humidities, ice is unstable, contrails (if generated) are only short-lived, and contrail cirrus advected into such a region would dissipate rapidly.

It is highly justified to assume water equilibrium in subsaturated conditions. Variations of the aerosol water content by the slowly changing particle composition are small and the time for $\mathrm{H}_{2} \mathrm{O}$ to equilibrate with liquid aerosol particles is extremely short $(\ll 1 \mathrm{~s})$. We calculate the amount of particulate water from $p_{w}$ and the actual concentrations of SA and OM in particles of radius $r$ at every time step by iterating the water equilibrium equation to find the water mass fraction $W$ :

$p_{w}=p_{w}^{\mathrm{sat}}(W, T, r)$.

Here $p_{w}^{\text {sat }}$ is the saturation $\mathrm{H}_{2} \mathrm{O}$ vapor pressure over the solution including the Kelvin effect in each radius bin for each particle type (Luo et al., 1995). The particle water content is obtained from $W$, which is defined as the ratio of the water mass to the total (water plus soluble) mass per particle. To calculate the soluble mass, we treat $\mathrm{OM}_{\text {ambient }}$ and $\mathrm{OM}_{\text {aircraft }}$ as SA but consider only half of the respective OM mass to account for the typically lower hygroscopicity of OM compared to SA. The BC cores themselves are assumed to be hydrophobic, i.e. pure BC particles do not take up any substantial amount of water.

Table 1 lists the dry lognormal mode diameters of the four background particle types, along with their species volume fractions after equilibrium water uptake. Figure 2 shows the corresponding size distributions of the particles including the water fraction. To compute the total (wet) mode diameters, we determine an equilibrium growth factor according to

$\mathrm{GF}=\left[\frac{\rho_{\mathrm{SA}}(T)}{\rho(W, T)} \frac{1}{1-W}\right]^{1 / 3}$,

where $\rho$ is the solution bulk mass density and $\rho_{\mathrm{SA}}$ is the density of pure sulfuric acid. As the $\mathrm{BC}$ volume fractions are very small, the dry mode diameters are multiplied by GF to obtain the final ambient particle sizes. Values for GF range between 1.57 and 1.64 , depending on the relative humidity of the background case.

\subsection{Uncertainties}

The processes described in Sects. 2.1-2.4 are operator-split. The time step increases progressively with plume age by a factor 1.005 , starting with a value of $0.2 \mathrm{~s}$ that is held constant in the vortex regime. The time step is not allowed to increase beyond a small fraction of the simulation time, and is always much smaller than the time scales discussed above. This results in a high accuracy of the numerical solutions.

Using a stationary size grid in solving the coagulation equations, two coagulating particles form a larger particle a fraction of which is partitioned between two adjacent bins, conserving total particle volume. This creates some numerical diffusion, which we minimize by using a small bin volume ratio of 1.38 .

Uncertainties in ambient concentrations of $\mathrm{SO}_{2}$ will not seriously affect our results, because most of the $\mathrm{H}_{2} \mathrm{SO}_{4}$ condensing onto plume particles stems from the emitted $\mathrm{SO}_{2}$. The results may change quantitatively upon variations in soot emissions and plume dilution histories, but our qualitative arguments and principal conclusions will not change.

Brownian diffusion is well understood and validated for spherical particles. However, fractal BC particles may behave differently. According to laboratory experiments, coagulation scavenging of combustion aerosols has been found to occur at faster rates than predicted by Brownian diffusion theory (Hagen et al., 1991). The enhancement of coagulation kernels may be caused by effects of non-sphericity and/or charge effects. We refrain from adopting enhanced coagulation rates, because it is uncertain if the dry (uncoated) polystryrene latex particles that acted as collector particles in the experiments behave like tropospheric particles. Increased coagulation rates would accelerate the formation of mixed particles containing aircraft soot over the results presented in Sect. 3.

We keep the $\mathrm{SO}_{2}$ concentrations and properties of particles entrained into the plume constant. This implies that a blend of external processes beyond our control acts to maintain the prescribed values, although these might change with time. To this end, we are aware that we can only treat case studies with clearly defined boundary conditions, but we believe that we capture the most important cases in using four representative background aerosol distributions. More importantly, this approach is a serious option to develop or improve subgridscale parameterizations of soot-induced cirrus formation in global models.

We assume the plume to be homogeneously mixed at any time, an approximation that degrades as the plume ages because the area over which species must mix instantaneously increases with time. This is an inherent problem with any plume model and can only be overcome by introducing at least one spatial coordinate. However, we believe that the basic conclusions drawn from our model are robust and a larger numerical effort would merely add more detail, rather than affect our findings.

\section{Model results and discussion}

\subsection{General features}

We discuss the general features of plume evolution with the help of Fig. 4, displaying the time history of $\mathrm{SO}_{2}$ and $\mathrm{OM}$ concentrations normalized to background values (top left), the volume and mass mixing ratios of $\mathrm{H}_{2} \mathrm{SO}_{4}$ and total $\mathrm{BC}$, respectively (top right), and the total number concentrations of the key particle types (bottom). We have chosen the winter 
background distribution and an average FSC to highlight the main points; the other cases behave qualitatively similar.

The total OM concentration behaves like a chemically inert tracer. The amount of emitted OM (top left panel) exceeds that contained in background aerosol by a factor of 20 . After a short, slow decay phase during the vortex regime, the OM mixing ratio decreases more rapidly and approaches the ambient value (contained in entrained background aerosols) after about $10 \mathrm{~h}$.

Sulfur dioxide is initially 35 times more abundant than the assumed background concentration (50 ppt). Plume dilution reduces most of the emitted $\mathrm{SO}_{2}$ after several hours of plume age, and $\mathrm{SO}_{2}$ entrained from the background atmosphere takes over the dominant part (solid red curve). This is illustrated by a simulation without $\mathrm{SO}_{2}$ emissions, showing the evolution of entrained $\mathrm{SO}_{2}$ only (dashed red curve, top left panel). Sulfur dioxide is additionally affected by gas phase oxidation. In contrast to $[\mathrm{OM}],\left[\mathrm{SO}_{2}\right]$ starts to fall below its background level after $2 \mathrm{~d}$, because by then it becomes efficiently oxidized to $\mathrm{H}_{2} \mathrm{SO}_{4}$ with an e-folding time scale of $5 \mathrm{~d}$, compare Sect. 2.4.

The total $\mathrm{BC}$ mixing ratio (top right panel) exhibits the same tracer-like evolution as OM, except that the assumed wintertime background concentration of $2.5 \mathrm{ng} / \mathrm{kg}$-air is not approached even at $t=48 \mathrm{~h}$, where $\mathrm{BC}_{\text {aircraft }}=15 \mathrm{ng} / \mathrm{kg}$-air. In the background cases SUM, ACC, and NUC, we prescribe $\mathrm{BC}_{\mathrm{ambient}}=7.5 \mathrm{ng} / \mathrm{kg}$-air; here $\mathrm{BC}_{\text {aircraft }}$ is twice as large at the end of the simulation. This implies that on the plume scale, most of the BC by mass (and even more so by number) stems from the nonvolatile aircraft particles.

The $\mathrm{H}_{2} \mathrm{SO}_{4}$ mixing ratio (solid red curve) decays much faster than by dilution alone because of additional condensational losses (see below) that take place on a time scale of $t=1 \mathrm{~min}$ initially, as shown in Sect. 2.4. At $t=10 \mathrm{~min}$, $\left[\mathrm{H}_{2} \mathrm{SO}_{4}\right]$ starts to rise due to oxidation of $\mathrm{SO}_{2}$. The comparison of the solid and dashed red curves (top right panel) computed with and without $\mathrm{SO}_{2}$ emissions quantifies the production of additional $\mathrm{H}_{2} \mathrm{SO}_{4}$ vapor by oxidation of emitted plus entrained versus entrained $\mathrm{SO}_{2}$ as the difference of these two curves. At $1-2 \mathrm{~d},\left[\mathrm{H}_{2} \mathrm{SO}_{4}\right]$ starts to decrease again. On these time scales, plume $\mathrm{SO}_{2}$ is oxidized at a faster rate than it can be replaced by freshly entrained $\mathrm{SO}_{2}$. Hence the chemical source of plume $\mathrm{H}_{2} \mathrm{SO}_{4}$ weakens and condensation onto plume aerosols becomes more important.

Within $5-10 \mathrm{~min}$, the emitted $\mathrm{H}_{2} \mathrm{SO}_{4}$ is mainly taken up by the volatile plume aerosols, which are initially present in very high total concentrations of $n_{\mathrm{V}}=2 \times 10^{9} \mathrm{~cm}^{-3}$ (bottom panel), decreasing rapidly to $5 \times 10^{6} \mathrm{~cm}^{-3}$ at $t=5 \mathrm{~min}$ due to self-coagulation. The initial self-coagulation time scale is given by $1 /\left(C_{\mathrm{V}, \mathrm{V}} n_{\mathrm{V}}\right)=1 \mathrm{~s}$, with the coagulation coefficient $C_{\mathrm{V}, \mathrm{V}}=5 \times 10^{-10} \mathrm{~cm}^{3} \mathrm{~s}^{-1}$. This condensation contributes to the growth of particles in the $\mathrm{V}$ distribution, enhances their mean size, and hence slows their coagulation rates with larger plume particles. A simulation with $\mathrm{SO}_{2}$ but without $\mathrm{H}_{2} \mathrm{SO}_{4}$ emissions (dotted red curve, top right panel) supports this explanation. $\mathrm{No} \mathrm{H}_{2} \mathrm{SO}_{4}$ is available for condensation initially, as it is only slowly chemically generated.

The concentrations of particles in the $\mathrm{N}$ distribution falls to zero within the first few time steps, and is therefore not visible. This happens because $\mathrm{N}$ particles are transformed into VN particles by scavenging of small particles from the $\mathrm{V}$ distribution (Table 3 ). This process occurs on a time scale of $1 /\left(C_{\mathrm{N}, \mathrm{V}} n_{\mathrm{V}}\right)=0.2 \mathrm{~s}$, with $C_{\mathrm{N}, \mathrm{V}}=3 \times 10^{-9} \mathrm{~cm}^{3} \mathrm{~s}^{-1}$ and the initial $n_{\mathrm{V}}$ value from above. The same argument applies to particles from the distribution NA. Once these form by hetero-coagulation between emitted $\mathrm{N}$ and entrained A particles, scavenging of $\mathrm{V}$ particles transforms them into MX particles on a similar time scale. In contrast, A particles are not readily depleted by transformation to VA and MX because they are continuously replenished by entrainment.

The total initial concentration of VN particles is practically equal to the emitted soot concentration and slowly decays owing to dilution and formation of MX particles, reaching about $10 \mathrm{~cm}^{-3}$ at $t=2 \mathrm{~d}$. Entrainment of $\mathrm{A}$ and subsequent coagulation with $\mathrm{V}$ leads to a roughly constant level of A+VA particles in the plume comparable to the background aerosol concentration (Table 1). As the final product of coagulation processes, the total concentration of MX particles increases more slowly, but reaches values comparable to $\mathrm{VN}$ at the end of the simulation.

In sum, mixing ratios of $\mathrm{BC}_{\text {aircraft }}$ well above background $\mathrm{BC}$ values are present within 1-2 days after emission and constitute a significant perturbation of the refractory component of plume aerosols. The key role of the $\mathrm{V}$ distribution consists of feeding SA and $\mathrm{OM}_{\text {aircraft }}$ into the particle types VA, VN, and MX, all of which contain BC and OM in various amounts and from various sources. Emissions of $\mathrm{H}_{2} \mathrm{SO}_{4}$ and $\mathrm{H}_{2} \mathrm{SO}_{4}$ photochemically produced from $\mathrm{SO}_{2}$ further enhance the amount of soluble matter contained in plume aerosols. The A and VA distributions provide a reservoir of $\mathrm{BC}_{\mathrm{ambient}}$-containing particles that mix with emissions containing $\mathrm{BC}_{\text {aircraft }}$ to generate $\mathrm{MX}$ particles. The $\mathrm{N}$ and NA distributions are numerically unimportant and need not be considered further.

\subsection{Number and volume distributions}

The size distributions of number (black) and volume (red) concentration after $t=24 \mathrm{~h}$ are shown in Fig. 5 for the four background cases and for the three FSCs (thin curves). The background distributions are also shown (thick curves), for comparison. Figure 6 displays the total volume distributions along with the concentrations of the chemical species contained in the plume particles, but for medium FSC only.

In Fig. 5, a marked enhancement of particle number at small $D \approx 0.01 \mu \mathrm{m}$ is seen in all cases. The strongest enhancements occur with the WIN and NUC distributions, which offer much less surface area to scavenge the small plume aerosols than the SUM and ACC distributions. For a given background case, the increases are most pronounced at high 

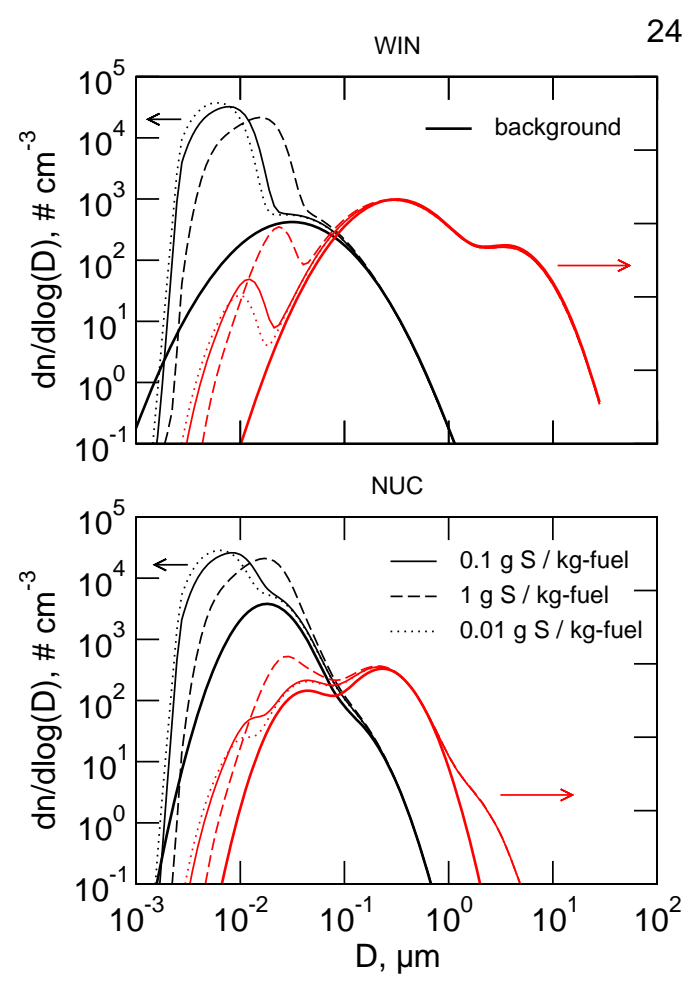

24 hours
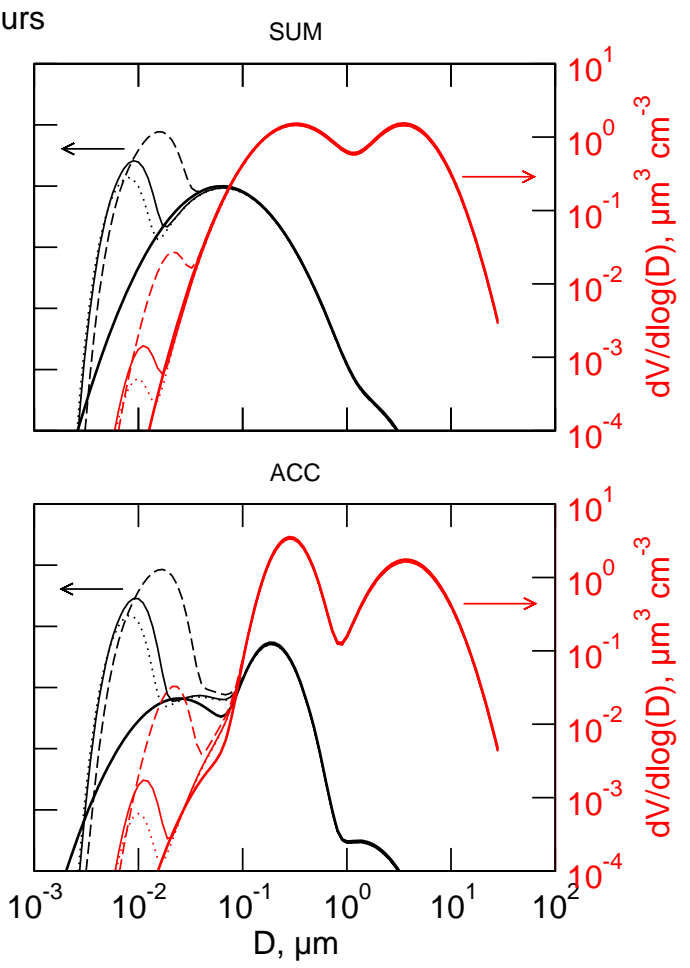

Fig. 5. Total number and volume distributions for the four background aerosol cases $24 \mathrm{~h}$ after emission for three FSCs. For comparison, the background distributions are shown as thick curves in each panel.

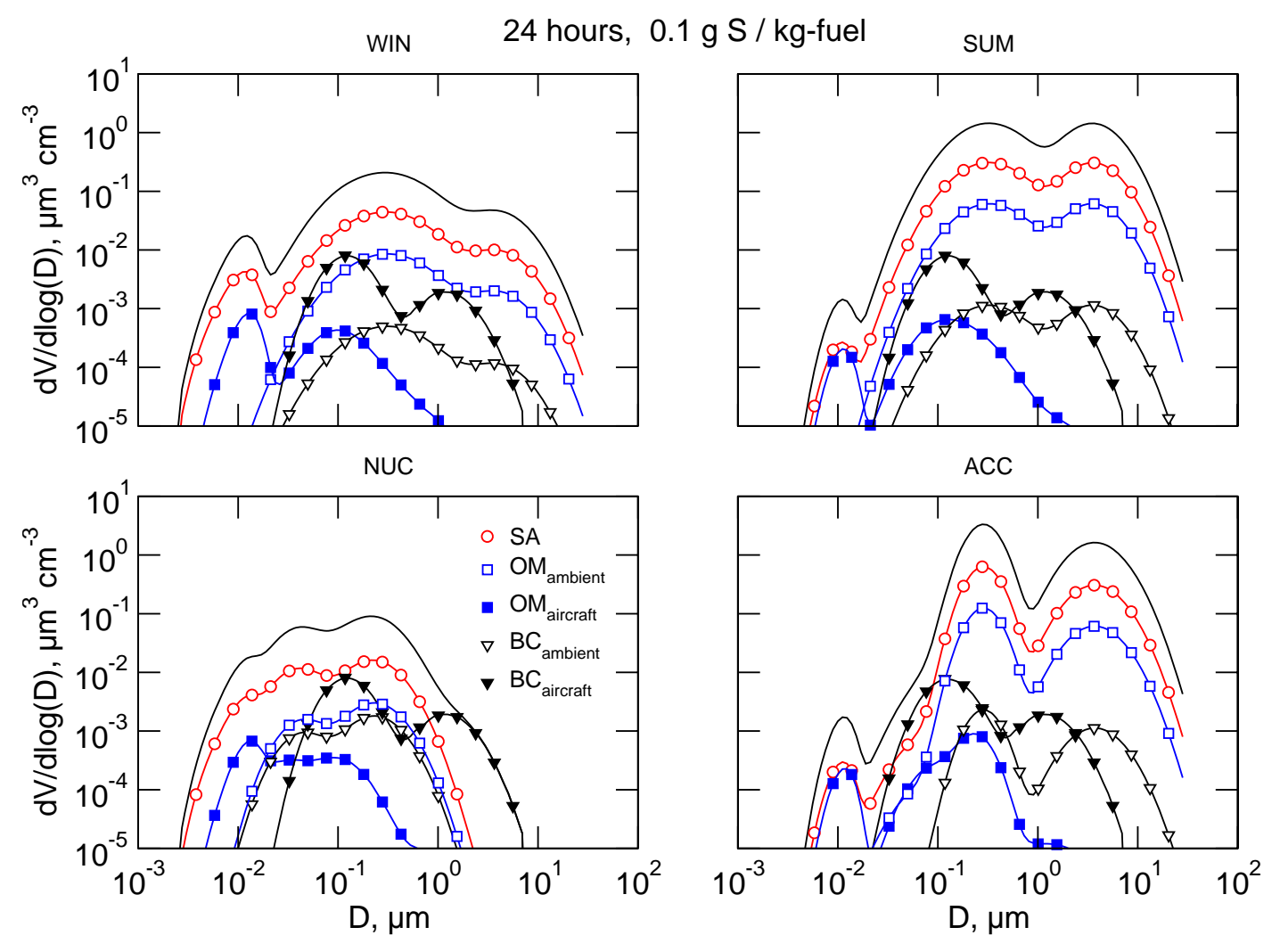

Fig. 6. Total and species volume distributions for the four background aerosol cases $24 \mathrm{~h}$ after emission for medium FSC. 
24 hours, $0.1 \mathrm{~g} \mathrm{~S} / \mathrm{kg}$-fuel
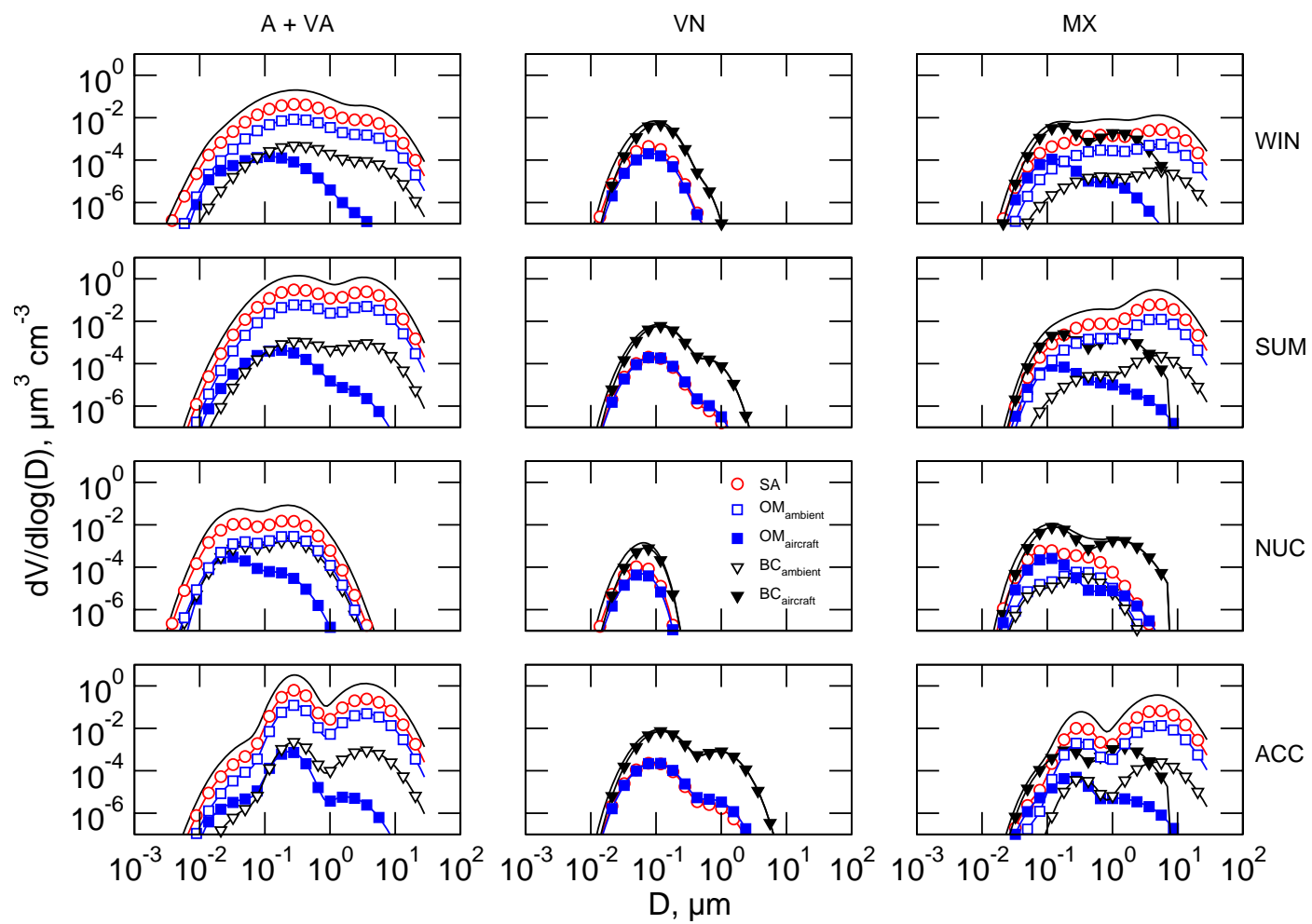

Fig. 7. As in Fig. 6, but splitted up into different particle types.

FSC (dashed), indicating that they are caused by the addition of the small, mainly sulfur-containing $\mathrm{V}$ particles. The small difference between the medium (solid) and low (dotted) fuel sulfur cases is caused by the presence of OM in the volatile particles, keeping the perturbation high even when the volatile emissions contain only little SA.

The high number of small particles in case NUC reduces the emission particles from the $\mathrm{V}$ distribution as efficient as the lower number of larger particles in case WIN, as the rate coefficients for coagulation scavenging scale $\propto n r^{2}$ for $D<0.1 \mu \mathrm{m}$, i.e. in the free molecular regime.

Changes in the background volume concentrations are generally less pronounced. Aircraft-produced SA and OM from the volatile emissions typically produce a further mode in the $0.01-0.1 \mu \mathrm{m}$ diameter range, which is also obvious from Fig. 6. Only in case NUC, the volume is increased also at large sizes $(\sim 5 \mu \mathrm{m})$. Figure 6 shows that this is caused by $\mathrm{BC}$-containing particles from the nonvolatile emissions.

Despite their large number, $\mathrm{V}$ particles are not expected to significantly alter cirrus formation because of their very small size and the insensitivity of the homogeneous freezing process to changes in the volatile particle size distribution (Kärcher et al., 2006). However, organics contained in the V (and VA) particles might affect nucleation, as further examined in Sect. 4.2.

Figure 7 repeats this information for individual particle types (mainly ambient, A+VA; mainly aircraft soot, VN; final mixture MX). All distributions contain various amounts of $\mathrm{OM}$ and $\mathrm{BC}$ from ambient and aircraft sources, depending on size. The A+VA distributions contain excess OM from aircraft emissions at small sizes. The $\mathrm{VN}$ distributions are dominated by $\mathrm{BC}_{\text {aircraft }}$ and $\mathrm{OM}_{\text {aircraft }}$, being the only particle type lacking ambient contributions. The MX distributions show the most complex partitioning between $\mathrm{BC}$ and $\mathrm{OM}$ from ambient and aircraft sources. The size-dependent distributions of chemical species in different plume particles sheds some light on the complexity of freezing processes possibly causing an indirect aircraft effect on cirrus clouds. We will reiterate this issue in Sect. 4.

Our results are consistent with in-situ measurements in the plume near-field, as remarked in Sect. 2.1. Several studies have attempted to quantify the regional or global scale particle perturbations due to aircraft emissions based on in-situ observations (Fahey et al., 1995; Hofmann et al., 1998; Anderson et al., 1999; Schröder et al., 2000) and global modeling (Danilin et al., 1998; Rahmes et al., 1998; Kjellström et al., 1999; Hendricks et al., 2004). The key results are that aircraft-induced increases in tropospheric sulfate and BCcontaining particles are small by mass but can be significant by number. The perturbation is more important above than below the tropopause owing to the longer residence time of lower stratospheric emissions. Note that besides chemical 
composition, the number concentration enhancement is important for the indirect effect on cirrus clouds.

Several issues render a quantification of the far-field perturbation level diffcult, among which are the sparsity of farfield observations, the large variability of upper tropospheric aerosols in the Aitken size range, uncertainties in extrapolating from near-field measurements to larger scales, and the possible presence of clouds that act to strongly reduce the aircraft particle emissions due to efficient scavenging by cloud particles. The results shown in Figs. $4-7$ will be affected by transport and mixing processes before they can be regarded as a realistic regional perturbation. These processes can only be treated within a global model after appropriate parameterization of the plume processes studied in this work.

In sum, emissions from aircraft engines lead to a variety of complex, mixed particles. These particles contain either only volatile components (SA and OM) or volatile and nonvolatile (soot) components. Particle number concentrations and species volume fractions vary between different particle types, and their chemical composition additionally depends on the size. The most complex particle type MX originates from internal mixing with ambient particles. The particle type most closely resembling the original nonvolatile emissions is $\mathrm{VN}$, which is dominated by $\mathrm{OM}$ and $\mathrm{BC}$, but also contains significant amounts of SA. The aqueous SA and OM coating of $\mathrm{VN}$ particles increases as the plume ages. The combined particle type A+VA represents perturbed ambient aerosols entrained into the plume, while $\mathrm{V}$ is the decaying ultrafine, fully soluble component of the emissions.

\section{Potential for soot-induced cirrus formation}

To evaluate the potential of aircraft emissions to modify cirrus cloud formation, we need to judge the ice nucleation efficiency of individual particle types in the temperature and humidity range of the aging plume. To put this discussion on a solid basis, we first review the current state of laboratory studies of ice nucleation, then motivate typical cirrus formation scenarios, highlight atmospheric implications, and finally address possibilities to mitigate the indirect effect.

\subsection{Laboratory studies of ice nucleation by soot particles}

Only a few laboratory studies have addressed the ice nucleation properties of soot particles at $T<233 \mathrm{~K}$. To a great extent, most studies have used idealized soot particles of unknown relevance for atmospheric soot. DeMott et al. (1999) investigated the ice nucleation ability of BC particles ("lamp black" from Degussa Corporation, Frankfurt/Main, Germany) at $213-233 \mathrm{~K}$ using a continuous flow diffusion (CFD) chamber (Rogers et al., 1998). Particles were dispersed from soot samples on the vibrating surface of a speaker. The resulting aerosol particles with mean mobility equivalent diameters of about $240 \mathrm{~nm}$ (aggregates of primary particles of average size $95 \mathrm{~nm}$ ) were either directly passed to the CFD chamber or first coated with an approximate monolayer or multilayer of $\mathrm{H}_{2} \mathrm{SO}_{4}$ molecules. The soluble mass fractions were estimated as $0.3 \%$ and $2 \%$, respectively, and no size change was detectable by a Differential Mobility Analyzer for the coatings used. The BET specific surface area was stated as $20 \mathrm{~m}^{2} / \mathrm{g}$; later experiments using Degussa soot with a much larger surface area of $420 \mathrm{~m}^{2} / \mathrm{g}$ showed that these samples were not more ice nucleation active.

The untreated particles and those with monolayer coverage activated ice only at a relative humidity close to water saturation (Fig. 8, DS untreated and $\mathrm{DS}_{2} \mathrm{SO}_{4}$ monolayer). The threshold for ice nucleation by $1 \%$ of the particles varied from about $100 \%$ relative humidity with respect to water at $233 \mathrm{~K}$ to $93 \%$ at $213 \mathrm{~K}$. This corresponds to ice saturation ratios, $S_{i}$, of 1.5 and 1.6, respectively. In experiments with multilayer $\mathrm{H}_{2} \mathrm{SO}_{4}$ coverage (Fig. 8, $\mathrm{DS}_{2} \mathrm{SO}_{4}$ multilayer) ice nucleation by $1 \%$ of the particles occurred at $S_{i}$ between 1.55 at $228 \mathrm{~K}$ and 1.33 at $213 \mathrm{~K}$. These thresholds are below the homogeneous freezing thresholds of soluble particles (Koop et al., 2000) only at $T<220 \mathrm{~K}$. The lower and upper threshold curves are calculated for $1 \%$ of the solution particles with radii $1 \mu \mathrm{m}$ and $0.1 \mu \mathrm{m}$ to freeze within $100 \mathrm{~s}$ and $1 \mathrm{~s}$, respectively.

From this we conclude that only a multilayer $\mathrm{H}_{2} \mathrm{SO}_{4}$ coverage and cold temperatures render the Degussa soot particles more efficient IN than liquid solution particles. The greater acidic coverage must facilitate greater water uptake, although it is not clear how this increases the ice nucleation efficiency at low temperatures. The mechanism by which ice forms on the soot surface in contact with the aqueous $\mathrm{H}_{2} \mathrm{SO}_{4}$ layer in the immersion mode remains unknown. For instance, it is not known how thick a layer must be to permit the formation of ice germs by immersion. We point out that for thin (monolayer) coatings, there is no clear distinction between deposition and immersion nucleation modes.

Möhler et al. (2005a) used soot particles from a graphite spark generator (GS) for ice nucleation studies at $T=185-240 \mathrm{~K}$. These particles had a fractal-like, agglomerate structure with mean mobility equivalent diameters of $70-140 \mathrm{~nm}$ and large specific surface areas of $\sim 300 \mathrm{~m}^{2} / \mathrm{g}$. Untreated GS particles and GS particles coated with $\mathrm{H}_{2} \mathrm{SO}_{4}$ were used in different experiments in the cloud chamber AIDA of Forschungszentrum Karlsruhe. The coated particles had mean diameters in the range $90-200 \mathrm{~nm}$ and $\mathrm{H}_{2} \mathrm{SO}_{4}$ volume fractions between $\sim 20-80 \%$. Figure 8 shows the ice nucleation threshold of $0.1-0.3 \%$ of untreated GS particles to vary from $S_{i}$ values 1.3 at $186 \mathrm{~K}$ to 1.4 at $240 \mathrm{~K}$, with minimum values of 1.1 at $215 \mathrm{~K}$. After coating with $\mathrm{H}_{2} \mathrm{SO}_{4}$, the onset thresholds range from 1.55 at $185 \mathrm{~K}$ to 1.4 at $230 \mathrm{~K}$ (Fig. 8, $\mathrm{GS} \mathrm{H}_{2} \mathrm{SO}_{4}$ coating). These thresholds are significantly higher compared to the untreated GS particles, but still below the homogeneous freezing range.

Between 215 and $220 \mathrm{~K}$, the ice nucleation onsets of DS soot with multilayer $\mathrm{H}_{2} \mathrm{SO}_{4}$ coverage and $\mathrm{H}_{2} \mathrm{SO}_{4}$-coated GS 


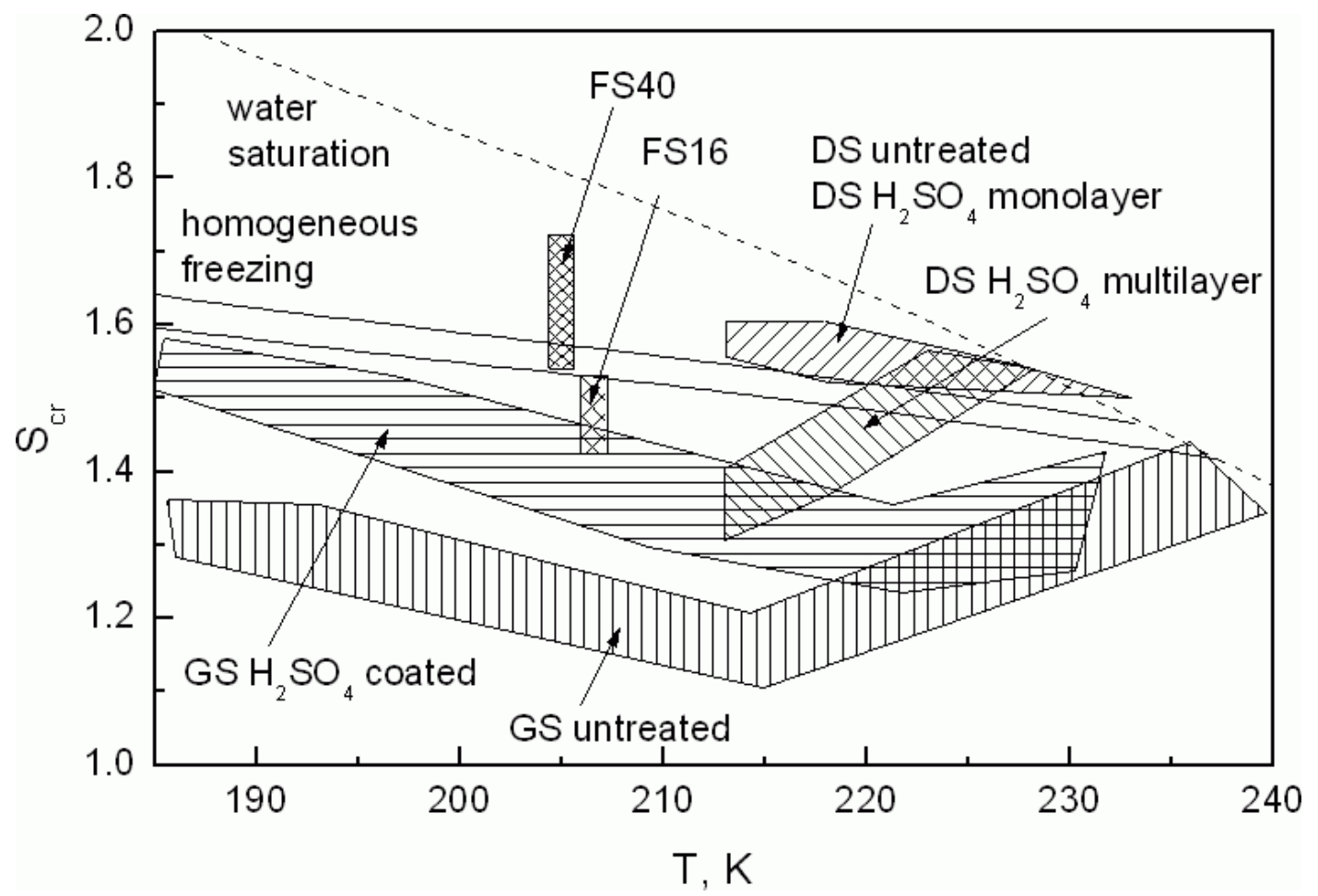

Fig. 8. Summary of threshold ice saturation ratios describing the onset of heterogeneous ice nucleation by soot particles measured in laboratory studies. Threshold ranges are shown for ice nucleation by: $1 \%$ Degussa soot (DS) untreated particles, and with $\mathrm{H}_{2} \mathrm{SO}_{4} \mathrm{monolayer}$ and multilayer coating (DeMott et al., 1999); 0.1-0.3\% untreated and $\mathrm{H}_{2} \mathrm{SO}_{4}$-coated soot particles (GS) from a graphite spark generator (Möhler et al., 2005a); and 0.1-1\% flame soot particles with 16\% (FS16) and 40\% (FS40) organic carbon content (Möhler et al., 2005b). Also shown is the dashed water saturation curve (Murphy and Koop, 2005) and the solid curve for the onset of homogeneous freezing of solution particles (Koop et al., 2000). The data from Möhler et al. (typical relative uncertainty $\pm 5 \%$ for warmer $T$ and $\pm 10 \%$ for colder $T$ ) and DeMott et al. (maximum relative uncertainty $\pm 3 \%$ ) are calculated with vapor pressure relationships from Murphy and Koop (2005) and Buck (1981), respectively.

soot agree with each other. The increasing difference at warmer $T$ may be caused by differences in coating thicknesses or different surface structures of the DS and GS particles. It is not clear why the $\mathrm{H}_{2} \mathrm{SO}_{4}$-coated DS particles show a steeper $T$-dependence of the nucleation thresholds than the $\mathrm{H}_{2} \mathrm{SO}_{4}$-coated GS particles. Regardless, the results for both soot samples suggest that at least at $T<225 \mathrm{~K}$, sulfuric acid coated soot particles of some type are capable of nucleating ice below the homogeneous freezing thresholds.

The causes responsible for the marked difference between the ice nucleation onsets of untreated GS particles and DS particles without coating or with monolayer $\mathrm{H}_{2} \mathrm{SO}_{4}$ coverage are not understood. This difference cannot be caused by instrumental artifacts or measurement uncertainties, but is related to different physical or chemical surface properties of the DS and GS particles. Further laboratory studies are needed to resolve this issue.

In addition to $\mathrm{H}_{2} \mathrm{SO}_{4}$, OC in emitted aerosols or contained in ambient aerosols contributes to the chemical composition of the plume particle mixtures. Möhler et al. (2005b) employed the AIDA to investigate the ice nucleation ability of soot particles with different OC content generated in a propane burner with different fuel-to-air ratios. At $T=207 \mathrm{~K}$, $0.1-1 \%$ of flame soot particles with $16 \%$ OC mass content (FS16 in Fig. 8) nucleated ice at $S_{i} \simeq 1.45$, somewhat below the homogeneous freezing thresholds. At the same temperature, ice nucleation onset by flame soot with $40 \%$ OC content (FS40 in Fig. 8) was observed at $S_{i}=1.5-1.7$, i.e. close to or slightly above the homogeneous freezing levels. At a peak $S_{i}$ of 1.9 very close to water saturation, still fewer than $1 \%$ of all soot particles were active as IN. No significant water uptake was observable.

A suppressed IN activity for thicker OC coatings was confirmed recently in similar AIDA experiments using flame soot particles from the same propane burner. At a temperature of $226 \mathrm{~K}$, about $20 \%$ of the low OC content particles activated ice at $S_{i}=1.1-1.3$. Increasing the OC content by variation of the flame conditions again markedly suppressed the ice nucleation activity. (More details of these measurements will be published elsewhere.) From these results it is evident that increasing the OC content makes the flame soot particles more hydrophobic and suppresses water condensation and therefore ice nucleation. The hydrophobic nature of high $\mathrm{OC}$ content flame soot was also observed in 
experiments between $240-245 \mathrm{~K}$. However, the mere presence of OC may not be an adequate descriptor of hygroscopicity. Instead, the general impact of OC may depend on the nature of the combustion process and fuel, so, for instance, may not be uniform for jet fuel combustion versus biomass burning.

At temperatures above $235 \mathrm{~K}$, recent laboratory studies report little, if any, ice activity of different soot samples (Dymarska et al., 2006; Kanji and Abbatt, 2006). Only a minor fraction of soot particles acted in the immersion mode after water condensation. The requirement of water saturation at the warmest temperatures is in agreement with the results for DS and untreated GS (Fig. 8), which also show ice nucleation activity only close to or slightly above water saturation. Earlier studies by DeMott (1990) showed 0.1\% and 1\% of acetylene-produced soot particles effective as IN in simulated adiabatically-cooling cloud parcels at $249 \mathrm{~K}$ and $239 \mathrm{~K}$, respectively. The studies by Diehl and Mitra (1998) and Gorbunov et al. (2001) report relatively large number fractions of soot containing droplets to freeze at temperatures as high as $253 \mathrm{~K}$ and $268 \mathrm{~K}$, respectively. The latter study did not well document aerosol concentration and size distribution as well as ice particle measurements during the mixing-type cloud chamber experiments. The results from this study at relatively warm temperatures have not been reproduced in more recent studies and so should not be extrapolated to cold cirrus temperatures. Diehl and Mitra (1998) investigated the freezing of large water droplets with diameters $0.3-0.8 \mathrm{~mm}$ suspended in a vertical wind tunnel. Each droplet probably contained a large number of soot particles, which was not specified. Therefore it is not possible to relate the fraction of frozen droplets to the soot particle number or mass in the droplets. Freezing could have been induced by a minor fraction of the soot particles immersed in the droplet. Again, the results should probably not be extrapolated to cirrus conditions.

We cannot draw a definite conclusion about size effects on heterogeneous ice nucleation. The existing data might indicate a moderate dependence on size for bare particles, with higher nucleation thresholds for smaller particles, but this becomes less clear once the particles are coated with hygroscopic material. In this context, we recall that most aircraftemitted soot particles are actually smaller than $100 \mathrm{~nm}$ in diameter (see Sect. 2.1 and Table 1). To better assess the role of aircraft soot in ice formation, more systematic laboratory studies of ice nucleation by small soot particles are required.

The above discussion of laboratory studies of ice nucleation by soot aerosol particles can be summarized as follows:

(I) In the temperature range 213-233 K, Degussa lamp black soot without coating or with monolayer $\mathrm{H}_{2} \mathrm{SO}_{4}$ coverage activates ice only above the homogeneous freezing thresholds near water saturation. The same soot particles with multilayer $\mathrm{H}_{2} \mathrm{SO}_{4}$ coverage show ice nucleation by $1 \%$ of the particles below the homogeneous freezing thresholds only below $220 \mathrm{~K}$.
(II) About $0.1-0.3 \%$ of soot particles from a graphite spark generator are ice active at low ice saturation ratios ranging from 1.3 at $186 \mathrm{~K}$ to 1.4 at $240 \mathrm{~K}$, with minimum values of about 1.1 at $215 \mathrm{~K}$. A similar small number fraction of the same particles immersed in aqueous $\mathrm{H}_{2} \mathrm{SO}_{4}$ show a slightly enhanced ice nucleation onset between 1.55 at $185 \mathrm{~K}$ and 1.4 at $230 \mathrm{~K}$ before homogeneous freezing could set in.

(III) Flame soot aerosol particles with an OC mass content of $16 \%$ showed ice nucleation onset at $S_{i}=1.45$ clearly below the homogeneous freezing thresholds at $T=207 \mathrm{~K}$. A recent study extends this finding, indicating that ice nucleation thresholds decrease to values $1.1-1.3$ at $226 \mathrm{~K}$ for flame soot particles with similar OC content. Increasing the OC content to $40 \%$ markedly suppresses the ice nucleation efficiency of flame soot, at least as caused by variations of flame soot generation in the laboratory.

(IV) At temperatures above $235 \mathrm{~K}$, a wide range of ice nucleation activity has been observed for soot particles from various sources. The most recent studies show little, or modest, ice nucleation activity of soot particles in the immersion mode. Some earlier studies that inferred high IN activity for soot aerosols were poorly quantified. Further study is needed to clarify the role of other ice nucleation modes such as contact freezing (Sastry, 2005).

We have emphasized that more laboratory studies are needed to understand the differences in ice nucleation behavior of soot particles from various sources. Most recent works to be published elsewhere (Koehler et al., 2007' ; DeMott et al., 2007 $\mathrm{a}^{2} ; \mathrm{b}^{3}$ ) suggest that there is a range of ice nucleation behaviors at low $T$ from hydrophobic soot requring water activation for freezing, to moderately IN active. For these extreme case particles, hygroscopicity tends to more ice formation toward the homogeneous freezing limit, or ice nucleation at moderately lower relative humidities.

\subsection{Ice formation by dust and mixed-phase particles}

We briefly summarize findings concerning the ice nucleation ability of mineral dust particles, which are key competitors of soot and liquid aerosols during ice formation in the atmosphere.

It has long been known that mineral dusts can act as efficient heterogeneous IN in a wide range of temperature conditions (Pruppacher and Klett, 1997). A number of laboratory studies suggest that pure dust particles from various sources including atmospheric samples and appropriate surrogates,

\footnotetext{
${ }^{1}$ Koehler, K., Petters, M. D., DeMott, P.J., et al.: Cloud condensation nuclei activity and ice nucleation ability of selected combustion particles, Atmos. Chem. Phys. Discuss., in preparation, 2007.

${ }^{2}$ DeMott, P. J., Petters, M. D., Prenni, A. J., et al.: Cloud activation behaviors of some diesel exhaust particles, J. Geophys. Res., in preparation, 2007a.

${ }^{3}$ DeMott, P. J., Petters, M. D., Prenni, A. J., et al.: Ice nucleation behavior of biomass combustion particles, Atmos. Chem. Phys. Discuss., in preparation, $2007 \mathrm{~b}$.
} 
clays, and mineral components internally mixed or coated with sulfate and organics, are effective IN (Zuberi et al., 2002; Hung et al., 2003; Archeluta et al., 2005; Möhler et al., 2006; Knopf and Koop, 2006; Kanji and Abbatt, 2006).

Evidence from field observations exists that mineral particles, fly ash, and metallic particles far from their source regions may serve at times as IN in cirrus clouds, in some cases also without being associated with significant acidic or other condensed components (Heintzenberg et al., 1996; Chen et al., 1998; DeMott et al., 2003; Sassen et al., 2003; Cziczo et al., 2004; Twohy and Poellot, 2005; Richardson et al., 2007). These IN components are disproportionally enriched in these components in total aerosols, whose overall chemical composition is dominated by sulfates and organics. At the same time, some of these field measurements suggest that soot, while apparently being present as IN across the tropospheric temperature regime, constitute only a minor fraction in apparent IN.

As a general conclusion from the above-mentioned laboratory studies, we note that the onset ice saturation values for heterogeneous nucleation on dust particles are often seen to be as low as $S_{i}=1-1.25$ in cirrus conditions, but $S_{i}=1.3-1.4$ for $200 \mathrm{~nm}$ diameter Asian dust particles and $S_{i}=1.35-1.5$ for kaolinite and montmorillonite immersed in super- $\mu \mathrm{m}$ aqueous $\left(\mathrm{NH}_{4}\right)_{2} \mathrm{SO}_{4}$ droplets has also been reported. Perhaps not surprising, and similar to some soot samples, dust particles and their surrogates often nucleate ice over a range of $S_{i}$-values $(\sim 10-20 \%)$, which can be attributed to different nucleation characteristics of individual particles contained in the various samples. Particle size effects in heterogeneous ice formation are noted (Archeluta et al., 2005), with larger particles (>100 nm) causing ice nucleation at lower $S_{i}$ than smaller particles in the same temperature range. Dust particles do not always appear to be good IN depending on their surface conditions. So far, only few studies have examined the effect of coatings on dust-induced ice nucleation.

While the homogeneous freezing process involving supercooled liquid particles appears to be quite well understood (Koop et al., 2000; Möhler et al., 2003; Haag et al., 2003b; Abbatt et al., 2006), uncertainties remain concerning the formation of crystalline organic and inorganic phases within partially soluble aerosols such as ammonium sulfate and certain organics, in particular oxalic acid (Zuberi et al., 2001; Abbatt et al., 2006; Zobrist et al., 2006; Shilling et al., 2006; Beaver et al., 2006). In several cases, ice formation in mixedphase particles is observed to compete with deliquescence of crystalline solids at low supersaturations $\left(S_{i}-1<0.4-0.5\right)$. This could bring about more complicated pathways to form cirrus than by fully insoluble IN alone. Depending on the exact chemical composition of the liquid phase, these freezing pathways might apply to the $\mathrm{V}$ and VA particle types. Because organics appear to be ubiquitous in liquid particles (cf. Sect. 2.1.2), this constitutes an important uncertainty in assessing the atmospheric soot effect on cirrus.

\subsection{Cirrus formation scenarios}

Next, we outline the conditions in which soot particles from aircraft might alter cirrus microphysical properties.

In Fig. 9 we present results from a physically-based parameterization scheme for cirrus formation from multiple aerosol types in adiabatically rising air parcels (Kärcher et al., 2006). This scheme has originally been designed for use in global models and validated against detailed numerical simulations. Despite a number of underlying simplifications, its results are quantitatively reliable and robust. Note that the assumption of single threshold values for IN is an idealization, as real IN might nucleate ice over an extended range of ice saturation ratios.

Figure 9 shows the total number densities of ice crystals, $n_{i}$, as a function of soot particle number density, $n_{s}$. Besides $n_{s}$, several other crucial parameters are varied in these calculations: (i) the vertical wind speed, $w$, ranging from purely synoptic uplift (top panel) via mean values typically observed on the mesoscale (middle panel) to lee wave or convective forcing (bottom panel); (ii) the abundance of mineral dust particles as indicated by the legends, with concentrations $n_{d}$ rising with $w$; and (iii) the threshold saturation ratios $S_{c r}$ for ice nucleation by the soot particles as given at the top of the figure, whereby the highest value is below but close to the homogeneous threshold. The number size distribution of liquid $\mathrm{H}_{2} \mathrm{SO}_{4} / \mathrm{H}_{2} \mathrm{O}$ particles and the assumed sizes of dust and soot particles are given in the figure caption. The results are insensitive to variations of the liquid particle properties. The choice of IN sizes is guided by the fact that the ice-active particle population is mainly found in the size range above $\sim 100 \mathrm{~nm}$ in atmospheric observations (DeMott et al., 2003; Richardson et al., 2007) and that soot particles from combustion are typically smaller than soil-derived dust particles.

Dust and soot particles are assumed to be monodisperse. This captures their main effects and the poor knowledge about their atmospheric size distributions does not warrant more details to be included in this type of simulations.

In all panels in Fig. 9, the black curves denote the dependence of $n_{i}$ versus $n_{s}$ without interference by dust particles. In the limit of small $n_{s}, n_{i}$ arises exclusively from homogeneous freezing of liquid particles, and soot does not play any role in ice formation. The number of ice crystals formed by homogeneous freezing increases from $0.05 \mathrm{~cm}^{-3}$ to $10 \mathrm{~cm}^{-3}$ when the updraft speed increases from $5 \mathrm{~cm} / \mathrm{s}$ to $100 \mathrm{~cm} / \mathrm{s}$, highlighting the sensitive dependence of $n_{i}$ on the cooling rate. Increasing $n_{d}$ in this limit (from black via blue to red curves) decreases $n_{i}$ roughly by a factor of 2 (blue curves) and 5 (red curves) in each panel. These early formed ice crystals enhance the $\mathrm{H}_{2} \mathrm{O}$ losses due to depositional growth, and thereby reduce the rate of increase of supersaturation, which causes fewer liquid particles to freeze homogeneously.

This indirect aerosol effect in cirrus clouds appears when one type of IN is added to a liquid aerosol population. Because $n_{i}$ decreases when IN are added (in contrast to 


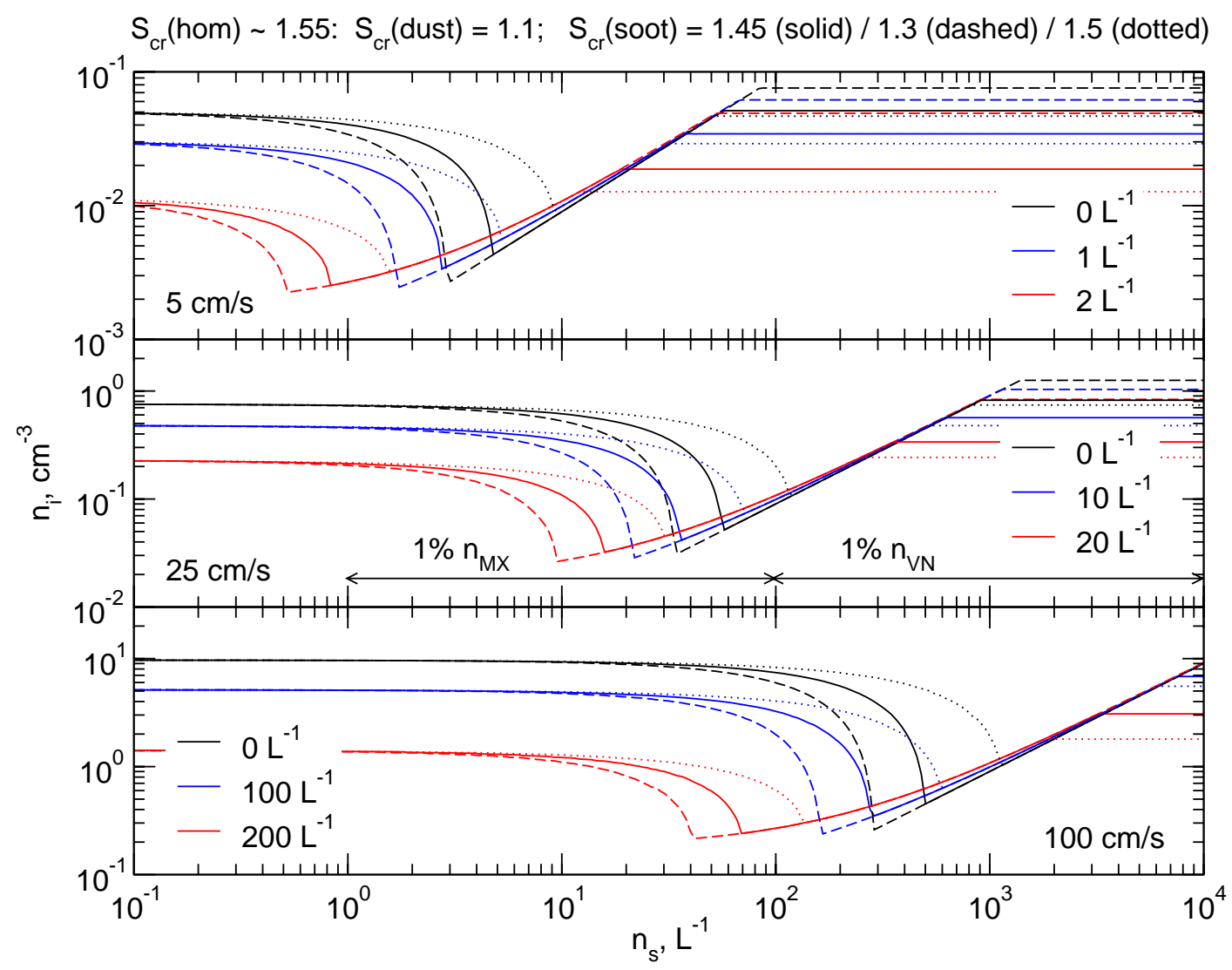

Fig. 9. Calculated total number density of nucleated ice crystals as a function of assumed soot particle number density. The curves result from competition of three particle types during ice formation in adiabatically rising air parcels. The ice nucleation thresholds of these particle types are given at the figure top. Results are shown for updraft speeds of $5 \mathrm{~cm} / \mathrm{s}$ (top panel, synoptic-scale vertical wind, no variability in mesoscale vertical air motions), $25 \mathrm{~cm} / \mathrm{s}$ (middle panel, corresponding to typically observed background mesoscale temperature fluctuations), and $100 \mathrm{~cm} / \mathrm{s}$ (bottom panel, representative for strong updrafts in orographic waves or near convection). The air parcels start rising at $250 \mathrm{hPa}$ and $220 \mathrm{~K}$ at ice saturation and contain mineral dust particles with concentrations noted in the legends, a wide range of soot particle concentrations $n_{S}$ as indicated, and $500 \mathrm{~cm}^{-3}$ lognormally distributed aqueous $\mathrm{H}_{2} \mathrm{SO}_{4}$ particles with $D=100 \mathrm{~nm}$ and $\sigma=2$. Dust and soot particles are assumed to be monodisperse with diameters of $400 \mathrm{~nm}$ and $200 \mathrm{~nm}$, respectively. The two arrows in the middle panel indicate the range of number concentrations of BC-containing type MX and VN particles typical for far-field plume ages up to 2 days from Fig. 4, assuming that $1 \%$ of those are active IN. As for the concentration units, we note that $1 \mathrm{~cm}^{-3}=10^{3} \mathrm{~L}^{-1}$.

increased cloud droplet number caused by enhanced cloud condensation nuclei in liquid clouds), we have previously called this a negative Twomey effect (Kärcher et al., 2006). Satellite observations of polluted aerosol and cloud properties over the Indian Ocean lend support for the existence of a negative Twomey effect in the atmosphere (Chylek et al., 2006).

In our scenarios, dust particles are the most efficient IN, nucleating ice at $S_{\mathrm{cr}}=1.1$. Their highest concentrations in Fig. 9 have been chosen such that homogeneous freezing still occurs at any given $w$ in the limit of small $n_{s}$. Upon increasing $n_{s}$, soot particles exert an additional negative Twomey effect by nucleating ice at $S_{\mathrm{cr}}=1.3,1.45,1.5$ (dashed, solid, dotted curves). These ice crystals add to the preexisting crystals originating from the dust IN and amplify the negative Twomey effect. The soot effects would be larger than dis- cussed below, if soot particles were better IN than assumed here.

The ice concentration $n_{i}$ falls as soon as $n_{s}$ exceeds a certain limit, which depends on $w, n_{d}$, and the $S_{\mathrm{cr}}$-values of soot. For example, in a mesoscale updraft with $w=25 \mathrm{~cm} / \mathrm{s}$, $n_{s}$ must exceed $\sim 10 \mathrm{~L}^{-1}$ for $n_{d}=10 \mathrm{~L}^{-1}$ and $S_{\mathrm{cr}}=1.45$. This $n_{s}$-limit increases with increasing $w$ (to counteract a larger cooling rate) and $S_{\mathrm{cr}}$ (to compensate less efficient IN activity), and it decreases with increasing $n_{d}$ (to still allow homogeneous freezing to eventually take place).

Upon increasing the soot concentrations above these $n_{S^{-}}$ limits, we enter a regime in which $n_{i}$ rises in proportion to the available $n_{s}$. All curves collapse to a single relationship irrespective of $n_{d}$ and $S_{\mathrm{cr}}$. Further increasing $n_{s}$ leads to constant $n_{i}$. In this asymptotic case, the final $n_{i}$ is determined by the number of soot particles that nucleate ice at any given $w$ 
and is slightly higher (within a factor 2) than $n_{i}$ formed for the smallest $n_{s}$-values. Hence, adding a large number of soot particles leads to a traditional Twomey effect that increases the number of cloud particles, but which is typically weaker than the negative Twomey effect occurring at intermediate values of $n_{s}$.

\subsection{Atmospheric implications}

We now relate the laboratory measurements to our model results and evaluate conceivable cirrus changes. We use the soot concentration $n_{s}$ as a synonym for either $n_{\mathrm{MX}}$ or $n_{\mathrm{VN}}$, depending on which soot particle type actually nucleates ice in the plume. Here, $n_{\mathrm{MX}}$ stands for concentrations of ambient particles modified by aircraft BC emissions; the iceactive population $(D>100 \mathrm{~nm})$ consists of immersion nuclei, in which BC cores are surrounded by large masses of soluble $\mathrm{OM}$ and SA, and water, as inferred from the species volume fractions shown in Figs. 6 and 7. Further, $n_{\mathrm{VN}}$ are the number densities of original soot emissions modified by scavenged soluble matter; in these particles, the BC cores dominate the overall volume, and the initially small volume fraction of soluble OM and SA increases only slowly with time. The values $n_{\mathrm{MX}}$ and $n_{\mathrm{VN}}$ typically differ by two orders of magnitude, as can be inferred from Fig. 4. These concentration ranges are repeated in Fig. 9 as double arrows, assuming that $1 \%$ of them actually nucleate ice. This ice-active fraction is uncertain, but $1 \%$ is consistent with the onset of ice nucleation often measured in the laboratory (Sect. 4.1).

Referring to Fig. 8, the soot particles with $S_{\mathrm{cr}}$-values above the homogeneous freezing range would not actively participate in cirrus formation, but could still influence the number of $\mathrm{BC}$ inclusions within ice crystal residues. Once these ice crystals evaporate and release their soot cores, it is possible that the cores facilitate ice formation in a subsequent nucleation event by lowering the supersaturation threshold to form ice again (preacitvation). The mechanism of preactivation is poorly understood both theoretically and experimentally (Hobbs, 1974) and has previously been identified as being potentially relevant for dust (Knopf and Koop, 2006).

It is neither known how individual soot particle inclusions combine upon core release (i.e., fractionate into smaller pieces or aggregate into larger clusters) nor whether atmospheric soot particles including those from aircraft show preactivation effects. Owing to the fractal-like morphology of soot particles, it is possible that their ice nucleation efficiency may be affected by water-filled micropores even in water-subsaturated conditions due to a negative curvature effect (Suzanne et al., 2003). In this context, the formation of short-lived contrails (in a subsaturated atmosphere) may be of special relevance, because soot particles experience water supersaturations and the resulting droplets freeze when forming contrails (Kärcher et al., 1996).

Our discussion in Sect. 4.3 has shown that soot particles with $S_{\mathrm{cr}}$-values below the homogeneous freezing curve are capable of modifying cirrus properties, even if they are relatively poor IN $\left(S_{\mathrm{cr}} \geq 1.3\right)$. At a given cooling rate, the magnitude of the soot effect is mainly governed by the ratio $\left(n_{s} / n_{d}\right)$ and the range of $S_{\mathrm{cr}}$-values for soot IN. With the help of Figs. 8 and 9, we infer two main possibilities which can be summarized as follows.

(A) $\mathrm{VN}$ particles initiate ice formation at rather high $n_{s}>100 \mathrm{~L}^{-1}$, requiring soot particles with thin surface coatings acting as IN. This might lead to a slight increase (factor 2 at most) in $n_{i}$ for low to medium vertical wind speeds. At very high $w, n_{i} \propto n_{s}$, likely accompanied with a slight decrease of $n_{i}$ relative to homogeneous freezing except for very high concentrations of mineral dust IN.

(B) MX particles lead to ice formation at relatively low $n_{s}<100 \mathrm{~L}^{-1}$, implying that the ice-forming soot particles have a sufficiently thick surface coating or are immersed within large, liquid aerosol particles. This range of $n_{s^{-}}$ concentrations might lead to significant reductions in $n_{i}$ (factor 2-5), particularly for the commonly observed mesoscale range of $w$, including large portions of the contiguous synoptic and orographic/convective scales.

These two scenarios are expressed with the caveat that the ice nucleation efficiency of very small $(<100 \mathrm{~nm})$ soot particles has not been fully explored experimentally and that most aircraft-induced soot particles are indeed of such small sizes at emission and remain so in the plume, because selfcoagulation is slow.

We add three remarks to better judge our inferences.

First, dust particles are assumed to be very good IN to maximize their impact. If we assumed that dust particles were less perfect IN, then their concentrations would have to be higher than noted in Fig. 9 in order to exert similar effects on $n_{i}$. In this context, we note that in upper tropospheric background conditions, up to few tens of heterogeneous IN per liter of air is a realistic order of magnitude (DeMott et al., 2003; Haag et al., 2003a; Richardson et al., 2007), but up to a few hundered IN per liter have been observed in polluted air masses with substantial air traffic (Rogers et al., 1998). If the IN concentrations are even higher, as it is possible in aging aircraft plumes, then they might dominate ice formation even at relatively high updraft speeds (DeMott et al., 1997; Gierens, 2003), as noted above under (A).

Second, dust particles could be present in a fraction of the ambient particle populations A and VA, or included in A as external mixtures. For simplicity, we ignored a possible presence of ice-active dust in MX particles. In addition, we did not consider possible heterogeneous nucleation induced by crystalline phases in OM+SA mixtures as described in Sect. 4.2, because virtually nothing is known about their atmospheric relevance. If we included both, MX particles containing dust as effective IN and mixed phase organic/inorganic plume particles nucleating ice on their own, then the effect of soot aerosols on cirrus formation would be smaller than quantified above. 
Third, the magnitude of the indirect aerosol effects is maximized in idealized parcel simulations without consideration of sedimentation and variability in vertical wind speed, relative humidity, and other parameters. This has been demonstrated by including these effects in more complex simulations (Haag and Kärcher, 2004). In these simulations, the basic trends discussed above have been confirmed in principle, but the magnitude of changes seen in probability distributions of $n_{i}$, ice water content, effective radius, and cirrus cloud cover are somewhat weaker.

Closer inspection of Fig. 8 allows further potential implications about the soot-induced, indirect effect on cirrus to be drawn. The ice nucleation efficiency of GS particles maximizes between $215-225 \mathrm{~K}$, a regime including mean upper tropospheric temperatures where aircraft contrails frequently form. If real jet engine soot particles behaved like the GS particles, then the indirect effect triggered by VN particles would not (often) occur in the presence of contrail cirrus, despite their high efficiency to act as IN. This is plausible because the high ice crystal number concentrations in contrail cirrus will drive ice saturation ratios close to unity.

However, outside of but near the contrail plumes, MX particles that have interacted with ambient aerosols at earlier times and then behave like the GS particles could trigger additional ice formation. In aircraft corridors, this mechanism might lead to a diffuse background of thin cirrus sheets embedded in clusters of contrail cirrus. Scenes that are compatible with this hypothesis are frequently seen in satellite observations (H. Mannstein, personal communication, 2006).

We take the comparison with GS particles a step further and increase $T$ beyond $225 \mathrm{~K}$. Contrails then form less and less frequently, so that, on average, the indirect effect from MX and/or VN particles can dominate under favorable conditions, even when soot nucleation thresholds rise with increasing $T$, as for the GS particle samples shown in Fig. 8. Note that, at least for GS particles and unlike for $T<225 \mathrm{~K}$, the role of $\mathrm{H}_{2} \mathrm{SO}_{4}$ coatings is less important at high $T$.

If $\mathrm{VN}$ or MX particles behaved like the FS particles shown in Fig. 8, then their indirect effect would be negligible around $205 \mathrm{~K}$, similar to DS particles with small or no coating above $220 \mathrm{~K}$. More recent results from AIDA measurements (not shown) indicate substantially lower FS nucleation thresholds at higher $T(226 \mathrm{~K})$, a similar trend the coated DS particles exhibit with decreasing $T$. At least for the FS particle samples, organic-rich coatings of order $40 \%$ by mass would effectively shut off ice nucleation below homogeneous freezing. However, as stressed in Sect. 4.1, our present knowledge about the effects of coatings and particle size on ice nucleation is insufficient to draw a final conclusion.

\subsection{Possible mitigation options regarding aviation effects}

The VN and MX particles are directly affected by SA and $\mathrm{OM}$ emissions and are the key targets for mitigation strate- gies aimed at minimizing the aircraft soot-induced indirect effect on cirrus.

Based on our calculations (Fig. 9), a decrease in the soot number emission index (i.e. $n_{\mathrm{VN}}$ ) will not substantially change our conclusions expressed as scenario (A) in Sect. 4.4, unless this decrease is substantial (>90\%). Even in such a case, this might only increase the importance of scenario (B) at the expense of scenario (A) inasmuch as $n_{\mathrm{VN}}$ and $n_{\mathrm{MX}}$ then become comparable.

Based on the laboratory works, an increase in condensable organic emissions will increase the organic coating of VN particles, making them less ice-nucleation active. Current $\mathrm{OC}$ volume fractions on VN particles are low at emission ( $\sim \%$, Table 1$)$ and in the plume after $24 \mathrm{~h}$ (of order $10 \%$, Fig. 7, middle panel). (Mass fractions are roughly 1.5 times lower.) This implies that a large (perhaps more than five- to tenfold) increase in the OC emission index is probably required to effectively shut off ice nucleation on most of the VN particles. Current OC emissions mainly affect the upper tropospheric background aerosol in the Aitken mode in some cases (Figs. 5-7), but such a dramatic enhancement of OC emissions would generally modify the plume and background aerosols, with unknown effects on atmospheric chemistry and cloud formation.

We stress again that this would only hold under the premise that real aircraft soot cores in VN particles behave like the flame soot particles studied in the laboratory. Therefore, the above option to increase OC emissions must not be viewed as a recommendation.

We feel unable to address options to mitigate the iceforming efficiency of MX particles based on available evidence. Figure 7 (right panel) demonstrates that MX particles show a very complex, size-dependent partitioning between $\mathrm{BC}$ and $\mathrm{OM}$ from ambient and aircraft sources. If ice nucleation was triggered by the aircraft component, then minimizing the $\mathrm{BC}$ number emissions could help reduce the indirect effect caused by MX particles. Note that because of the high variability of background aerosol, it would be very difficult to accurately quantify the efficiency of such a mitigation strategy. Specifically, it is conceivable that the ambient BC and OM components (besides other possible IN) cause an indirect effect on their own, in which case we would expect a high geographical and seasonal variability of resulting cirrus modifications. The conflicting laboratory evidence concerning the role of acidic $\mathrm{H}_{2} \mathrm{SO}_{4}$ coatings on VN particles (GS versus DS particles in Fig. 8) does not enable us to formulate a mitigation option with respect to changes in the fuel sulfur content.

\section{Conclusions}

In this study, we have investigated the role of soot aerosols in cirrus cloud formation with a combination of processoriented modeling and evaluation of laboratory results of 
Table 4. Summary of uncertainties associated with the impact of soot particles on cirrus clouds in priority order. Abbreviations 'exp' and 'mod' indicate that the identified uncertainty is mainly relevant for experimental or modeling work, respectively.

\begin{tabular}{lccc}
\hline uncertainty & type & priority & section \\
\hline lack of direct in-situ observations & exp & high & $1.2,5$ \\
use of repesentative soot in laboratory studies & exp & high & 4.1 \\
impact of OC versus SA in ice nucleation (incl. liquid phase) & exp & high & 4.1 \\
size distribution of and speciation of OM in soot particles & exp & high & 2.1 \\
preactivation after contrail dissolution & $\exp$ & high & 4.4 \\
frequency of ice supersaturation & $\bmod$ & high & 1.1 \\
separation of dynamical and aerosol effects in cirrus formation & $\exp$ & high & 1.2 \\
basic understanding of heterogeneous ice nucleation & $\exp$ & $\operatorname{medium}$ & $4.1,4.2$ \\
aerosol representation in global models & $\bmod$ & $\operatorname{medium}$ & 5 \\
ambient $\mathrm{SO}_{2}$ concentrations & $\bmod$ & low & $2.4,2.5$ \\
plume dilution history & $\bmod$ & low & 2.2 \\
soot particle coagulation rates & $\bmod$ & low & 2.5 \\
\hline
\end{tabular}

heterogeneous ice nucleation. Because of the renewed debate about the climate impact of aviation and the possible prevalence of aircraft soot emissions in flight corridors, emphasis was put on the factors controlling ice formation in dispersing aircraft plumes in competition with ice-forming particles from other sources.

The key findings of this work have already been summarized at the end of Sects. 3.1, 3.2, and 4.1 (points (I)-(IV)). Conceivable cirrus changes caused by soot emissions have been highlighted in Sect. 4.4 (scenarios (A) and (B)) and potential mitigation options noted Sect. 4.5. The various uncertainties associated with the impact of soot particles on cirrus are collected in Table 4, providing a convenient point of focus for researchers who like to consider how to proceed to reduce these uncertainties.

Perhaps the largest problem in estimating the indirect effect of soot aerosols on cirrus is the lack of direct atmospheric observations together with the fact that most laboratory studies employed idealized soot samples of unknown atmospheric relevance. Effects of coatings and particle size on the ice nucleation efficiency have not been fully explored. It is possible that real atmospheric soot particles exhibit a wide range of ice nucleation activities, depending on their source and atmospheric aging processes. It seems likely that this range is narrower for aircraft-induced soot particles, the number, size, and chemical composition of which are relatively (but possibly not sufficiently) well defined. In this context, it is important to point out that the few atmospheric observations available to date suggest that soot constitutes only a minor fraction in apparent IN throughout the troposphere.

The inclusion of indirect aerosol effects in global models is at its infancy. As a first step, using well defined yet idealized assumptions about ice nucleation thresholds of various
IN types in parameterization schemes that track the competition between different IN during cirrus formation, global parametric model studies of indirect effects of soot and dust aerosols appear to be feasible in the near future. This can be achieved even without a detailed theoretical understanding of heterogeneous ice nucleation. More substantial progress in parameterizing heterogeneous ice nucleation rates requires a better understanding of basic mechanisms leading to the formation of ice germs on real IN surfaces, besides more laboratory studies in which particle sizes and coatings, ice-active particle fractions, and other parameters are varied systematically.

However, we are far away from realistically modeling the coupling between direct (contrail cirrus) and indirect (sootinduced cirrus) aviation effects on high cloudiness as outlined in Sect. 1.1. Meanwhile, process studies of the present type could be extended with a cirrus model and then used to study the indirect effect of soot emissions on cirrus nucleation in isolation, once we know how to treat ice nucleation in the various aerosol types that build up in the plume as a function of time. Such efforts should be complemented by coordinated atmospheric observations including airborne IN counters and aerosol mass spectrometers, quantification of black carbon in fine aerosols by selective detection of single particles, in-situ measurements of relative humidity and parameters determining the plume age, high resolution remote sensing, and meteorological forecasts of the formation and extent of ice supersaturated regions.

In this way, we hope to stimulate further research and contribute to an improved understanding of the aviation impact on cirrus cloudiness. 


\section{Notation}

FSC fuel sulfur content

IN heterogeneous ice nuclei

BC black carbon

OC particulate organic carbon

OM particulate organic matter

SA particulate sulfuric acid

W particulate water

$\mathrm{V}$ emitted volatile particles

$\mathrm{N}$ emitted nonvolatile particles

A entrained background (ambient) particles

$\mathrm{VN}$ coagulated particles resulting from $\mathrm{V}+\mathrm{N}$

VA coagulated particles resulting from $\mathrm{V}+\mathrm{A}$

NA coagulated particles resulting from $\mathrm{N}+\mathrm{A}$

MX coagulated particles resulting from $\mathrm{V}+\mathrm{NA}, \mathrm{N}+\mathrm{VA}$, $\mathrm{A}+\mathrm{VN}, \mathrm{VN}+\mathrm{VA}, \mathrm{VA}+\mathrm{NA}, \mathrm{NA}+\mathrm{VN}$

WIN wintertime background aerosol

SUM summertime background aerosol

NUC background aerosol after new particle formation

ACC background aerosol prior to cloud formation

Acknowledgements. This work contributes to the DLR/HGFproject PAZI-2, the HGF Virtual Institute ACI, and the EU-project SCOUT-O3. It was motivated by discussions during the joint SPARC/IGAC workshop on processes governing the chemical composition of the extratropical tropopause region held in Mainz, Germany, in 2005. Two of us (F. Yu and B. Kärcher) took advantage of summarizing recent scientific developments concerning the climate impact of aviation during a joint NASA/FAA workshop held in Boston, MA, USA, in 2006. We (S. Pechtl and B. Kärcher) thank M. Jacobson for providing us with his generic coagulation solver COAGBOX, which we modified for our purpose. We are grateful to U. Burkhardt, J. Hendricks, U. Schumann and the anonymous referees for valuable comments on this work and to H. Mannstein for useful discussions.

Edited by: T. Koop

\section{References}

Abbatt, J. P. D., Benz, S., Cziczo, D. J., Kanji, Z., Lohmann, U., and Möhler, O.: Solid ammonium sulfate aerosols as ice nuclei: A Pathway for cirrus cloud formation, Science, 313, 5794, 17701773, 2006.

Ackerman, S., Toon, O. B., Stevens, D. E., Heymsfield, A. J., Ramanathan, V., and Welton, E. J.: Reduction of tropical cloudiness, Science, 288, 1042-1047, 2000.

Anderson, B. E., Cofer, W. R., Crawford, J., Gregory, G. L., Vay, S. A., Brunke, K. E., Kondo, Y., Koike, M., Schlager, H., Baughcum, S. L., Jensen, E., Zhao, Y., and Kita, K.: An assessment of aircraft as a source of particles to the upper troposphere, Geophys. Res. Lett., 26, 3069-3072, 1999.

Archeluta, C. M., DeMott, P. J., and Kreidenweis, S. M.: Ice nucleation by surrogates for atmospheric mineral dust and mineral dust/sulfate particles at cirrus temperatures, Atmos. Chem. Phys.,
5, 2617-2634, 2005,

http://www.atmos-chem-phys.net/5/2617/2005/.

Baumgardner, D., Kok, G., and Raga, G.: Warming of the Arctic lower stratosphere by light absorbing particles, Geophys. Res. Lett., 31, L06117, doi:10.1029/2003GL018883, 2004.

Beaver, M. R., Elrod, M. J., Garland, R. M., and Tolbert, M. A.: Ice nucleation in sulfuric acid/organic aerosols: Implications for cirrus cloud formation, Atmos. Chem. Phys., 6, 3231-3242, 2006, http://www.atmos-chem-phys.net/6/3231/2006/.

Blake, D. F. and Kato, K.: Latitudinal distribution of black carbon soot in the upper troposphere and lower stratosphere, J. Geophys. Res., 100, 7195-7202, 1995.

Buck, A.L.: New equations for computing vapor pressures and enhancement factor, J. Appl. Meteorol., 20, 1527-1532, 1981.

Cantrell, W. and Heymsfield, A. J.: Production of ice in tropospheric clouds - a review, Bull. Amer. Meteorol. Soc., 86, 795807, 2005.

Chen, Y., Kreidenweis, S. M., McInnes, L. M., Rogers, D. C., and DeMott, P. J.: Single particle analysis of ice nucleation aerosols in the upper troposphere and lower stratosphere, Geophys. Res. Lett., 25, 1391-1394, 1998.

Cziczo, D. J., Murphy, D. M., Hudson, P. K., and Thomson, D. S.: Single particle measurements of the composition of cirrus ice residues during CRYSTAL-FACE, J. Geophys. Res., 109, D04201, doi:10.1029/2004JD004032, 2004.

Clarke, A. D., Shinozuka, Y., Kapustin, V. N., Howell, S., Huebert, B., Doherty, S., Anderson, T., Covert, D., Anderson, J., Hua, X., Moore II, K. G., McNaughton, C., Carmichael, G., and Weber, R.: Size distributions and mixtures of dust and black carbon aerosol in Asian outflow: Physiochemistry and optical properties, J. Geophys. Res., 109, D15S09, doi:10.1029/2003JD004378, 2004.

Chylek, P., Dubey, M. K., Lohmann, U., Ramanathan, V., Kaufman, Y. J., Lesins, G., Hudson, J., Altmann, G., and Olsen, S.: Aerosol indirect effect over the Indian Ocean, Geophys. Res. Lett., 33, L06806, doi:10.1029/2005GL025397, 2006.

Danilin, M. Y., Fahey, D. W., Schumann, U., Prather, M. J., Penner, J. E., Ko, M. K. W., Weisenstein, D. K., Jackman, C. H., Pitari, G., Köhler, I., Sausen, R., Weaver, C. J., Douglass, A. R., Connell, P. S., Kinnison, D. E., Dentener, F. J., Fleming, E. L., Berntsen, T. K., Isaksen, I. S. A., Haywood, J. M., and Kärcher, B.: Aviation fuel tracer simulations: Model intercomparison and implications, Geophys. Res. Lett., 25, 3947-3950, 1998.

DeMott, P. J.: An exploratory study of ice nucleation by soot aerosols, J. Appl. Meteorol., 29, 1072-1079, 1990.

DeMott, P. J., Rogers, D. C., and Kreidenweis, S. M.: The susceptibility of ice formation in upper tropospheric clouds to insoluble aerosol components, J. Geophys. Res., 102, 19575-19584, 1997.

DeMott, P. J., Chen, Y., Kreidenweis, S. M., Rogers, D. C., and Sherman, D. E.: Ice formation by black carbon particles, Geophys. Res. Lett., 26, 2429-2432, 1999.

DeMott, P. J., Cziczo, D. J., Prenni, A. J., Murphy, D. M., Kreidenweis, S. M., Thomson, D. S., Borys, R., and Rogers, D. C.: Measurements of the concentration abd composition of nuclei for cirrus formation, Proc. Natl. Acad. Sci., 100, 14 655-14 660, 2003.

Diehl, K. and Mitra, S. K.: A laboratory study of the effects of a kerosene burner exhaust on ice nucleation and the evaporation 
rate of ice crystals, Atmos. Environ., 32, 3145-3151, 1998.

Dymarska, M., Murray, B. J., Sun, L., Eastwood, M. L., Knopf, D. A., and Bertram, A. K.: Deposition ice nucleation on soot at temperatures relevant for the lower troposphere, J. Geophys. Res., 111, D04204, doi:10.1029/2005JD006627, 2006.

Fahey, D. W., Keim, E. R., Boering, K. A., Brock, C. A., Wilson, J. C., Jonsson, H. H., Anthony, S., Hanisco, T. F., Wennberg, P. O., Miake-Lye, R. C., Salawitch, R. J., Louisnard, N., Woodbridge, E. L., Gao, R. S., Donnelly, S. G., Wamsley, R. C., DelNegro, L. A., Solomon, S., Danube, B. C., Wofsy, S. C., Webster, C.R., May, R. D., Kelly, K. K., Loewenstein, M., Podolske, J. R., and Chan, K. R.: Emission measurements of the Concorde supersonic aircraft in the lower stratosphere, Science, 270, 70-74, 1995.

Gerz, Th., Dürbeck, T., and Konopka, P.: Transport and effective diffusion of aircraft emissions, J. Geophys. Res., 103, 25905 $25914,1998$.

Gierens, K.: On the transition between heterogeneous and homogeneous freezing, Atmos. Chem. Phys., 3, 437-446, 2003, http://www.atmos-chem-phys.net/3/437/2003/.

Gorbunov, B., Baklanov, A., Kakutkina, N., Windsor, H. L., and Tuomi, R.: Ice nucleation on soot particles, J. Aerosol Sci., 32, 199-215, 2001.

Haag, W., Kärcher, B., Ström, J., Minikin, A., Ovarlez, J., Lohmann, U., and Stohl, A.: Freezing thresholds and cirrus cloud formation mechanisms inferred from in situ measurements of relative humidity, Atmos. Chem. Phys., 3, 1791-1806, 2003 a.

Haag, W., Kärcher, B., Schaefers, S., Stetzer, O., Möhler, O., Schurath, U., Krämer, M., and Schiller, C.: Numerical simulations of homogeneous freezing processes in the aerosol chamber AIDA, Atmos. Chem. Phys., 3, 195-210, 2003b.

Haag, W. and Kärcher, B.: The impact of aerosols and gravity waves on cirrus clouds at midlatitudes, J. Geophys. Res., 109, D12202, doi:10.1029/2004JD004579, 2004.

Hagen, D. E., Trueblood, M. B., and Podzimek, J.: Combustion aerosol scavenging, Atmos. Environ., 25A, 2581-2586, 1991.

Hansen, J. and Nazarenko, L.: Soot climate forcing via snow and ice albedo, Proc. Natl. Acad. Sci., 100, 423-428, 2004.

Heintzenberg, J., Okada, K., and Ström, J.: On the composition of non-volatile material in upper tropospheric aerosols and cirrus crystals, Atmos. Res., 41, 81-88, 1996.

Hendricks, J., Kärcher, B., Döpelheuer, A., Feichter, J., Lohmann, U., and Baumgardner, D.: Simulating the global black carbon cycle: A revisit to the contribution of aircraft emissions, Atmos. Chem. Phys., 4, 2521-2541, 2004, http://www.atmos-chem-phys.net/4/2521/2004/.

Hendricks, J., Kärcher, B., Lohmann, U., and Ponater, M.: Do aircraft black carbon emissions affect cirrus clouds on the global scale?, Geophys. Res. Lett., 32, L12814, doi:10.1029/2005GL022740, 2005.

Hobbs, P. V.: Ice Physics, Clarendon Press, Oxford, UK, 837p., 1974.

Hofmann, D. J.: Twenty years of balloon-borne tropospheric aerosol measurements at Laramie, Wyoming, J. Geophys. Res., 98, 12 753-12 766, 1993.

Hofmann, D. J., Stone, R. S., Wood, M. E., Deshler, T., and Harris, J. M.: An analysis of 25 years of balloon-borne aerosol data in search of a signature of the subsonic commercial aircraft fleet, Geophys. Res. Lett., 25, 2433-2436, 1998.
Hung, H. M., Malinowski, A., and Martin, S. T.: Kinetics of heterogeneous ice nucleation on the surfaces of mineral dust coresinserted into aqueous ammonium sulfate particles, J. Phys. Chem. A, 107, 1296-1306, 2003.

Jacobson, M. Z.: Strong radiative heating due to the mixing state of black carbon in atmospheric aerosols, Nature, 409, 695-697, 2001.

Jacobson, M. Z.: Analysis of aerosol interactions with numerical techniques for solving coagulation, nucleation, condensation, dissolution, and reversible chemistry among multiple size distributions, J. Geophys. Res., 107, 4366, doi:10.1029/2001JD002044, 2002.

Jensen E. J. and Toon, O. B.: The potential impact of soot particles from aircraft exhaust on cirrus clouds, Geophys. Res. Lett., 24 249-252, 1997.

Jensen, E. J., Ackerman, A. S., Stevens, D. E., Toon, O. B., and Minnis, P.: Spreading and growth of contrails in a sheared environment, J. Geophys. Res., 103, 31 557-31 567, 1998.

Johnson, B. T., Shine, K. P., and Forster, P. M.: The semi-direct aerosol effect: Impact of absorbing aerosols on marine stratocumulus, Quart. J. Roy. Meteorol. Soc., 130, 1407-1422, 2004.

Kärcher, B.: Aviation-produced aerosols and contrails, Surv. Geophys., 20, 113-167, 1999.

Kärcher, B.: Contrails: Observations, formation mechanisms, atmospheric impacts, uncertainties, Research Report, Deutsches Zentrum f. Luft- u. Raumfahrt, DLR-Mitt., 2000-01, 47pp, 2000.

Kärcher, B. and Meilinger, S. K.: Perturbation of the aerosol layer by aviation-produced aerosols: A Parametrization of plume processes, Geophys. Res. Lett., 25, 4465-4468, 1998.

Kärcher, B. and Ström, J.: The roles of dynamical variability and aerosols in cirrus cloud formation, Atmos. Chem. Phys., 3, 823838, 2003, http://www.atmos-chem-phys.net/3/823/2003/.

Kärcher, B., Peter, Th., and Ottmann, R.: Contrail formation: Homogeneous nucleation of $\mathrm{H}_{2} \mathrm{SO}_{4} / \mathrm{H}_{2} \mathrm{O}$ droplets, Geophys. Res. Lett., 22, 1501-1504, 1995.

Kärcher, B., Peter, Th., Biermann, U. M., and Schumann, U.: The initial composition of jet condensation trails, J. Atmos. Sci., 53, 3066-3083, 1996.

Kärcher, B., Turco, R. P., Yu, F., Danilin, M. Y., Weisenstein, D. K., Miake-Lye, R. C., and Busen, R.: A unified model for ultrafine aircraft particle emissions, J. Geophys. Res., 105, 29379-29386, 2000.

Kärcher, B., Hendricks, J., and Lohmann, U.: Physicallybased parameterization of cirrus cloud formation for use in global atmospheric models, J. Geophys. Res., 111, D01205, doi:10.1029/JD006219, 2006.

Kanji, Z. A. and Abbatt, J. P. D.: Laboratory studies of ice formation via deposition mode nucleation onto mineral dust and n-hexane soot samples, J. Geophys. Res., 111, D16204, doi:10.1029/2005JD006766, 2006.

Kjellström, E., Feichter, J., Sausen, R., and Hein, R.: The contribution of aircraft emissions to the atmospheric sulfur budget, Atmos. Environ., 33, 3455-3465, 1999.

Knopf, D. A. and Koop, T.: Heterogeneous nucleation of ice on surrogates of mineral dust, J. Geophys. Res., 111, D12201, doi:10.1029/2005JD006894, 2006.

Koop, T., Luo, B. P., Tsias, A., and Peter, Th.: Water activity as the determinant for homogeneous ice nucleation in aqueous so- 
lutions, Nature, 406, 611-614, 2000.

Law, K., Pan, L., Wernli, H., Fischer, H., Haynes, P., Salawitch, R., Kärcher, B., Prather, M., Doherty S., and Ravishankara, A. R.: Processes governing the chemical composition of the extratropical UTLS, SPARC Newsletter No. 26, 8-19, 2006.

Liu, L. and Mishchenko, M. I.: Effects of aggregation on scattering and radiative properties of soot aerosols, J. Geophys. Res., 110, D11211, doi:10.1029/2004JD005649, 2005.

Luo, B. P., Carslaw, K. S., Peter, Th., and Clegg, S. L.: Vapour pressures of $\mathrm{H}_{2} \mathrm{SO}_{4} / \mathrm{HNO}_{3} / \mathrm{HCl} / \mathrm{HBr} / \mathrm{H}_{2} \mathrm{O}$ solutions to low stratospheric temperatures, Geophys. Res. Lett., 22, 247-250, 1995.

Marquart, S., Ponater, M., Mager, F., and Sausen, R.: Future development of contrail cover, optical depth, and radiative forcing: Impacts of increasing air traffic and climate change, J. Clim., 16, 2890-2904, 2003.

Minikin, A., Petzold, A., Ström, J., Krejci, R., Seifert, M., van Velthoven, P., Schlager, H., and Schumann, U.: Aircraft observations of the upper tropospheric fine particle aerosol in the northern and southern hemispheres at midlatitudes, Geophys. Res. Lett., 30, 1503, doi:10.1029/2002GL016458, 2003.

Minnis, P., Schumann, U., Doelling, D. R., Gierens, K., and Fahey, D. W.: Global distribution of contrail radiative forcing, Geophys. Res. Lett., 26, 1853-1856, 1999.

Möhler, O., Stetzer, O., Schaefers, S., Linke, C., Schnaiter, M., Tiede, R., Saathoff, H., Krämer, M., Mangold, A., Budz, P., Zink., P., Schreiner, J., Mauersberger, K., Haag, W., Kärcher, B., and Schurath, U.: Experimental investigations of homogeneous freezing of sulphuric acid particles in the aerosol chamber AIDA, Atmos. Chem. Phys., 3, 211-223, 2003, http://www.atmos-chem-phys.net/3/211/2003/.

Möhler, O., Büttner, S., Linke, C., Schnaiter, M., Saathoff, H., Stetzer, O., Wagner, R., Krämer, M., Mangold, A., Ebert, V., and Schurath, U.: Effect of sulfuric acid coating on heterogeneous ice nucleation by soot aerosol particles, J. Geophys. Res., 110, D11210, doi:10.1029/2004JD005169, 2005a.

Möhler, O., Linke, C., Saathoff, H., Schnaiter, M., Wagner, R., Mangold, A., Krämer, M., and Schurath, U.: Ice nucleation on flame soot aerosol of different organic carbon content, Meteorol. Z., 14, 477-484, 2005b.

Möhler, O., Field, P. R., Connolly, P., Benz, S., Saathoff, H., Schnaiter, M., Wagner, R., Cotton, R., Krämer, M., Mangold, A., and Heymsfield, A.: Efficiency of the deposition mode ice nucleation on mineral dust particles, Atmos. Chem. Phys., 6, 30073021, 2006,

http://www.atmos-chem-phys.net/6/3007/2006/.

Murphy, D. M., Thomson, D. S., and Mahoney, M. J.: In situ measurements of organics, meteoritic material, mercury, and other elements in aerosols at 5 to 19 kilometers, Science, 282, 16641669, 1998.

Murphy, D. M. and Koop, T.: Review of the vapour pressures of ice and supercooled water for atmospheric applications, Quart. J. Roy. Meteorol. Soc., 131, 1539-1565, 2005.

Murphy, D. M., Cziczo, D. J., Froyd, K. D., Hudson, P. K., Matthew, B. M., Middlebrook, A. M., Peltier, R. E., Sullivan, A., Thomson, D. S., and Weber, R. J.: Single-particle mass spectrometry of tropospheric aerosol particles, J. Geophys. Res., 111, D23S32, doi:10.1029/2006JD007340, 2006.

Murphy, D. M., Cziczo, D. J., Hudson, P. K., and Thomson, D. S.: Carbonaceous material in aerosol particles in the lower strato- sphere and tropopause region, J. Geophys. Res., 112, D04203, doi:10.1029/2006JD007297, 2007.

Novakov, T., Menon, S., Kirchstetter, T. W., Koch, D., and Hansen, J. E.: Aerosol organic carbon to black carbon ratios: Analysis of published data and implications for climate forcing, J. Geophys. Res., 110, D21205, doi:10.1029/2005JD005977, 2005.

Petzold, A., Döpelheuer, A., Brock, C. A., and Schröder, F.: In situ observations and model calculations of black carbon emission by aircraft at cruise altitude, J. Geophys. Res., 104, 22 171-22 181, 1999.

Ponater, M., Marquart, S., and Sausen, R.: Contrails in a comprehensive global climate model: parameterisation and radiative forcing results, J. Geophys. Res., 107, 4164, doi:10.1029/2001JD000429, 2002.

Pruppacher, H. R. and Klett, J. D.: Microphysics of Clouds and Precipitation, Kluwer Acad. Pub., Dordrecht, 976p., 1997.

Pueschel, R. F., Blake, D. F., Snetsinger, K. G., Hansen, A. D. A., Verma, S., and Kato, K.: Black carbon (soot) aerosol in the lower stratosphere and upper troposphere, Geophys. Res. Lett., 19, 1659-1662, 1992.

Rahmes, T. F., Omar, A. H., and Wuebbles, D. J.: Atmospheric distributions of soot particles by current and future aircraft fleets and resulting radiative forcing of climate, J. Geophys. Res., 103, 31 657-31 667, 1998.

Richardson, M. S., DeMott, P. J., Kreidenweis, S. M., Cziczo, D. J., Dunlea, E. J., Jimenez, J. L., Thomson, D. S., Ashbaugh, L. L., Borys, R. D., Westphal, D. L., Casuccio, G. S., and Lersch, T. L. Measurements of heterogeneous ice nuclei in the western United States in springtime and their relation to aerosol characteristics, J. Geophys. Res., 112, D02209, doi:10.1029/2006JD007500, 2007.

Roeckner, E., Stier, P., Feichter, J., Kloster, S., Esch, M., and Fischer-Bruns, I.: Impact of carbonaceous aerosol emissions on regional climate change, Clim. Dyn., 27, 553-571, 2006.

Rogers, D. C., DeMott, P. J., and Kreidenweis, S. M.: Measurements of ice nucleating aerosols during SUCCESS, Geophys. Res. Lett., 25, 1383-1386, 1998.

Sassen, K., DeMott, P. J., Prospero, J. M., and Poellot, M. R.: Saharan dust storms and indirect aerosol effects on clouds: CRYSTAL-FACE results, Geophys. Res. Lett., 30, 1633, doi:10.1029/2003GL017371, 2003.

Sastry, S.: Ins and outs of ice nucleation, Nature, 438, 746-747, 2005.

Sausen, R., Isaksen, I., Grewe, V., Hauglustaine, D., Lee, D. S., Myhre, G., Köhler, M. O., Pitari, G., Schumann, U., Stordal, F., and Zerefos, C.: Aviation radiative forcing in 2000: An update of IPCC (1999), Meteorol. Z., 14, 555-561, 2005.

Schnaiter, M., Linke, C., Möhler, O., Naumann, K.-H., Saathoff, H., Wagner, R., Schurath, U., and Wehner, B.: Absorption amplification of black carbon internally mixed with secondary organic aerosol, J. Geophys. Res., 110, D19204, doi:10.1029/2005JD006046, 2005.

Schröder, F., Brock, C. A., Baumann, R., Petzold, A., Busen, R. Schulte, P., and Fiebig, M.: In situ studies on volatile jet exhaust particle emissions: Impact of fuel sulfur content and environmental conditions on nuclei mode aerosols, J. Geophys. Res., 105, 19941-19954, 2000.

Schröder, F. P., Kärcher, B., Fiebig, M., and Petzold, A.: Aerosol states in the free troposphere at northern midlatitudes, J. Geo- 
phys. Res., 107, 8126, doi:10.1029/2000JD000194, 2002.

Schumann, U.: Formation, properties and climatic effects of contrails, C. R. Physique, 6, 549-565, 2005.

Schumann U., Schlager, H., Arnold, F., Baumann, R., Haschberger, P., and Klemm, O.: Dilution of aircraft exhaust plumes at cruise altitudes, Atmos. Environ., 32, 3097-3103, 1998.

Schumann U., Arnold, F., Busen, R., Curtius, J., Kärcher, B., Kiendler, A., Petzold, A., Schlager, H., Schröder, F., and Wohlfrom, K.-H.: Influence of fuel sulfur on the composition of aircraft exhaust plumes: The experiments SULFUR 1-7, J. Geophys. Res., 107, doi:10.1029/2001JD000813, 2002.

Schwarz, J. P., Gao, R. S., Fahey, D. W., Thomson, D. S., Watts, L. A., Wilson, J. C., Reeves, J. M., Baumgardner, D. G., Kok, G. L., Chung, S., Schulz, M., Hendricks, J., Lauer, A., Kärcher, B., Slowik, J. G., Rosenlof, K. H., Thompson, T. L., Langford, A. O., Lowenstein, M., and Aikin, K. C.: Single-particle measurements of midlatitude black carbon and light-scattering aerosols from the boundary layer to the lower stratosphere, J. Geophys. Res., 111, D16207, doi:10.1029/2006JD007076, 2006.

Shilling, J. E., Fortin, T. J., and Tolbert, M. A.: Depositional ice nucleation on crystalline organic and inorganic solids, J. Geophys. Res., 111, D12204, doi:10.1029/2005JD006664, 2006.

Stockwell, W. R. and Calvert, J. G.: The mechanism of the $\mathrm{HO}-\mathrm{SO}_{2}$ reaction, Atmos. Environ., 17, 2231-2235, 1983.

Strawa, A. W., Drdla, K., Ferry, G. V., Verma, S., Pueschel, R. F., Yasuda, M., Salawitch, R. J., Gao, R. S., Howard, D. D., Bui, P. T., Loewenstein, M., Elkins, J. W., Perkins, K. K., and Cohen, R.: Carbonaceous aerosol (soot) measured in the lower stratosphere during POLARIS and its role in stratospheric photochemistry, J. Geophys. Res., 104, 26 753-26 766, 1999.

Ström, J. and Ohlsson, S.: In-situ measurements of enhanced crystal number densities in cirrus clouds caused by aircraft exhaust, J. Geophys. Res., 103, 11 355-11 361, 1998.

Stuber, N., Forster, P., Rädel, G., and Shine, K.: The importance of the diurnal and annual cycle of air traffic for contrail radiative forcing, Nature, 441, 864-867, 2006.
Suzanne, J., Ferry, D., Popovitcheva, O., and Shonija, N. K.: Ice nucleation by kerosene soot under upper tropospheric conditions, Canad. J. Phys., 81, 423-429, 2003.

Twohy, C. H. and Poellot, M. R.: Chemical characteristics of ice residual nuclei in anvil cirrus clouds: Evidence for homogeneous and heterogeneous ice formation, Atmos. Chem. Phys., 5, 22892297, 2005, http://www.atmos-chem-phys.net/5/2289/2005/.

Wuebbles, D., Gupta, M., and Ko, M.: Evaluating the impacts of aviation on climate change, EOS Transactions, 88, 157-160, Full workshop report available from http://www.faa.gov, 2007.

Yu, F. and Turco, R. P.: The formation and evolution of aerosols in stratospheric aircraft plumes: Numerical simulations and comparisons with observations, J. Geophys. Res., 103, 25 91525 934, 1998.

Yu, F., Turco, R. P., and Kärcher, B.: The possible role of organics in the formation and evolution of ultrafine aircraft particles, J. Geophys. Res., 104, 4079-4087, 1999.

Zobrist, B., Marcolli, C., Koop, T., Luo, B. P., Murphy, D. M., Lohmann, U., Zardini, A. A., Krieger, U. K., Corti, T., Cziczo, D. J., Fueglistaler, S., Hudson, P. K., Thomson, D. S., and Peter, Th.: Oxalic acid as a heterogeneous ice nucleus in the upper troposphere and its indirect aerosol effect, Atmos. Chem. Phys., 6, 3115-3129, 2006, http://www.atmos-chem-phys.net/6/3115/2006/.

Zuberi, B., Bertram, A. K., Koop, T., Molina, L. T., and Molina, M. J.: Heterogeneous nucleation of aqueous particles induced by crystallized $\left(\mathrm{NH}_{4}\right)_{2} \mathrm{SO}_{4}-\mathrm{H}_{2} \mathrm{O}$, ice and letovicite, J. Phys. Chem., A 105, 6458-6464, 2001.

Zuberi, B., Bertram, A. K., Cassa, C. A., Molina, L. T., and Molina, M. J.: Heterogeneous nucleation of ice in $\left(\mathrm{NH}_{4}\right)_{2} \mathrm{SO}_{4}-\mathrm{H}_{2} \mathrm{O}$ particles with mineral dust immersions, Geophys. Res. Lett., 29, 1504, doi:10.1029/2001GL014289, 2002. 